\title{
The Biochemistry, Ultrastructure, and Subunit Assembly Mechanism of AMPA Receptors
}

\author{
Terunaga Nakagawa
}

Received: 1 October 2010 /Accepted: 2 November 2010 /Published online: 16 November 2010

(C) The Author(s) 2010. This article is published with open access at Springerlink.com

\begin{abstract}
The AMPA-type ionotropic glutamate receptors (AMPA-Rs) are tetrameric ligand-gated ion channels that play crucial roles in synaptic transmission and plasticity. Our knowledge about the ultrastructure and subunit assembly mechanisms of intact AMPA-Rs was very limited. However, the new studies using single particle EM and X-ray crystallography are revealing important insights. For example, the tetrameric crystal structure of the GluA2cryst construct provided the atomic view of the intact receptor. In addition, the single particle EM structures of the subunit assembly intermediates revealed the conformational requirement for the dimer-to-tetramer transition during the maturation of AMPA-Rs. These new data in the field provide new models and interpretations. In the brain, the native AMPA-R complexes contain auxiliary subunits that influence subunit assembly, gating, and trafficking of the AMPA-Rs. Understanding the mechanisms of the auxiliary subunits will become increasingly important to precisely describe the function of AMPA-Rs in the brain. The AMPA-R proteomics studies continuously reveal a previously unexpected degree of molecular heterogeneity of the complex. Because the AMPA-Rs are important drug targets for treating various neurological and psychiatric diseases, it is likely that these new native complexes will require detailed mechanistic analysis in the future. The current ultrastructural data on the receptors and the receptorexpressing stable cell lines that were developed during the course of these studies are useful resources for high
\end{abstract}

T. Nakagawa $(\triangle)$

Department of Chemistry and Biochemistry,

University of California, San Diego,

9500 Gilman Drive,

La Jolla, CA 92093, USA

e-mail: nakagawa@ucsd.edu throughput drug screening and further drug designing. Moreover, we are getting closer to understanding the precise mechanisms of AMPA-R-mediated synaptic plasticity.

Keywords AMPA-type ionotropic glutamate receptors . AMPA receptors · Glutamate receptors · Ionotropic glutamate receptors · Biochemistry · Ultrastructure $\cdot$ Subunit assembly mechanism $\cdot$ Subunit assembly $\cdot$ Subunit . Biosynthesis · Biosynthetic intermediates $\cdot$ Electron microscopy $\cdot$ EM $\cdot$ Single particle $\cdot$ Single particle EM $\cdot 3 D$ EM - Density map · Comparing EM density and X-ray structure $\cdot$ Cryo-negative stain single particle EM $\cdot$ CryoEM - Image reconstruction · Vesicle trafficking $\cdot$ Endoplasmic reticulum - Glycosylation X-linked mental retardation . Alzheimer's disease · Amyotrophic lateral sclerosis · Limbic encephalitis · Rasmussen's encephalitis · GluR1 · GluR2 · GluR3 · GluR4 · GluA1 · GluA2 · GluA3 · GluA4 · Stragazin • TARP - Cornichon · CNIH · CKAMP44 · SOL-1 - Lurcher . Membrane biochemistry · Synaptic plasticity · Synaptic transmission $\cdot$ Postsynaptic density $\cdot$ Cell biology

\section{Introduction}

The majority of fast excitatory synaptic transmission in the brain is mediated by AMPA ( $\alpha$-amino-3-hydroxy-5-methyl4-isoxazole propionic acid) receptors (AMPA-Rs), a subset of ligand-gated ion channels of the glutamate receptor family $[1,2]$. The function of AMPA-Rs is critical for synaptic plasticity. Their dysfunction relates to various neurological and psychiatric disorders. The diseases that are affected by AMPA-Rs include X-linked mental retardation, Alzheimer's disease, amyotrophic lateral sclerosis, limbic encephalitis, ischemic brain injury, and Rasmussen's encephalitis [3-14]. The ultrastructure, conformational 
changes, modulation by auxiliary proteins, subunit assembly mechanisms, trafficking, and localization are characteristics that define the function of AMPA-Rs. The precise understanding of the biophysical and cell biological properties of AMPA-Rs will reveal some of the important mechanisms of synaptic plasticity and assists in identifying therapeutic measures to the diseases affected by AMPA-Rs.

\section{The Primary Structure of the AMPA-R Subunits}

From 1989 to 1992, the genes that encode the glutamate receptor subunits were discovered and reported [15-21]. Recent publications in the field use the GluA1-4 nomenclatures to refer to the four AMPA-R subunits [22]. The protein products of the four AMPA-R subunits share homology and domain organization. Each subunit of AMPA-Rs consists of four major domains (Fig. 1a, b). The amino terminus is located in the extracellular space and forms the N-terminal domain (NTD) consisting of about 370 amino acids. The NTDs of glutamate receptors are homologous to the bacterial amino acid binding protein LIVBP and the ligand binding domains of the metabotropic glutamate receptors, also known as mGluRs [23, 24]. The NTD is followed by a linker sequence and connects to another extracellular domain, the ligand binding domain (LBD). The linker connection between the NTD and the LBD is made of about 17 amino acids. The primary structure of the LBD, made of about 270 amino acids, is subdivided into two separated sub-fragments denoted as S1 and S2 [25]. The LBD undergoes conformational changes resulting in channel gating upon glutamate binding. The polypeptide chain forming the LBD is interrupted between the S1 and S2 fragments by two membrane spanning segments (M1 and M3) and one re-entrant loop (M2). The fourth membrane spanning segment (M4) is located at the $\mathrm{C}$-terminal end of the S2 fragment. The channel poreforming transmembrane domain (TMD) consists of M1-M4 [26]. Finally, a relatively small C-terminal domain (CTD) extends into the cytoplasm, interacting with cytosolic proteins that regulate receptor anchoring and trafficking [27-30]. The length of the CTD ranges between 30 and 50 amino acids depending on the subunit.

The AMPA-R subunits are subject to alternative splicing and RNA editing [31]. The alternative splicing results in flip and flop isoforms that are different by only nine amino acids in the region encompassing S2 subfragment of the LBD and the linker between the LBD and M4. Each splice variant confers distinct channel properties to the AMPA-Rs [32]. The relative abundance of the flip/flop variants in the brain are developmentally regulated [33]. Nucleotide sequences of the mRNAs of AMPA-R subunits are enzymatically modified by the deaminase ADAR2 [34], introducing amino acids that are not encoded by the genome. This post-transcriptional modification, known as RNA editing, occurs in two locations in the AMPA-R subunits [35]. The first is the $R / G$ site located within the LBD immediately before the flip/flop splice site in GluA24 subunits, and the other is the $\mathrm{Q} / \mathrm{R}$ site only in GluA2 subunit located in the loop of the transmembrane segments $[36,37]$. The different molecular products produced by RNA editing have distinct trafficking, maturation, and gating properties [38]. Collectively, the alternative splicing and RNA editing adds to the molecular complexity and functional variety of AMPA-Rs in the brain.

\section{Molecular Composition of Native AMPA-Rs}

The core of the AMPA-R that forms the tetrameric ligandgated ion channel is made of the proteins encoded by the GluA1-4 genes (Fig. 1c, d). The core of most native AMPARs are heterotetramers made of at least two of the four proper AMPA-R subunits, GluA1-4 [39]. However, when overexpressed, an individual AMPA-R subunit is capable of assembling into a functional homotetrameric ligand-gated ion channel [40]. A series of works identified that trafficking of AMPA-Rs is governed by rules determined primarily by the subunit composition of the tetrameric core of the receptors, signifying the importance of the subunit composition in AMPA-R function [41-43]. Attached to the receptor core are the auxiliary subunits including stargazin/ TARPs (also known as g-2, g-3, g-4, g-5, g-7, and g-8) [44], cornichon 2/3 [45], and CKAMP44 (also known as Shisa9) [46]. Each auxiliary subunit has distinct function on receptor trafficking and/or gating [47]. The molecular complexity of the AMPA-Rs in brain is amplified by their co-assembly with the various transmembrane auxiliary subunits. In Caenorhabditis elegans, a transmembrane CUB domain containing protein SOL-1 interacts directly with the glutamate receptor subunit GLR-1 and is essential for glutamate receptor function [48]. The mammalian homologues of SOL1 are NETO-1 and -2. The SOL-1 homologues in rodents interact with kainate receptors [49] and NMDA receptors (NMDA-Rs) [50]. The membrane topology of each auxiliary subunit is shown in Fig. 1e.

\section{Overview of Ultrastructural Studies of AMPA-Rs}

In 1998, Eric Gouaux's laboratory reported the first structural data of the isolated LBD of AMPA-Rs [25]. The crystal structures of the isolated LBD, also known as the S1S2 construct, adopted a clamshell-like structure made of two lobes (D1 and D2 lobes). The ligand glutamate binds to the pocket of the clamshell and induces a conformational change resulting in the closure of the clamshell [51]. Furthermore, two clamshells form dimers in the crystal 

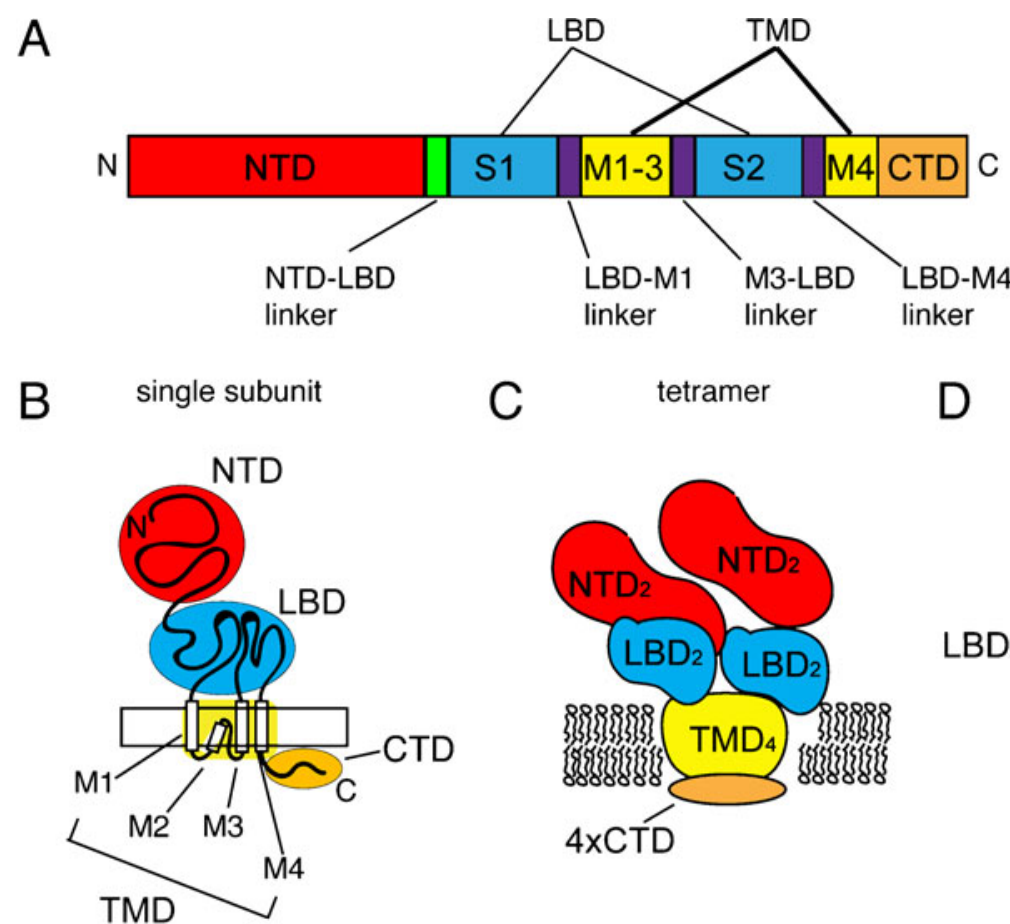

D EM image of GluA2 tetramer

E

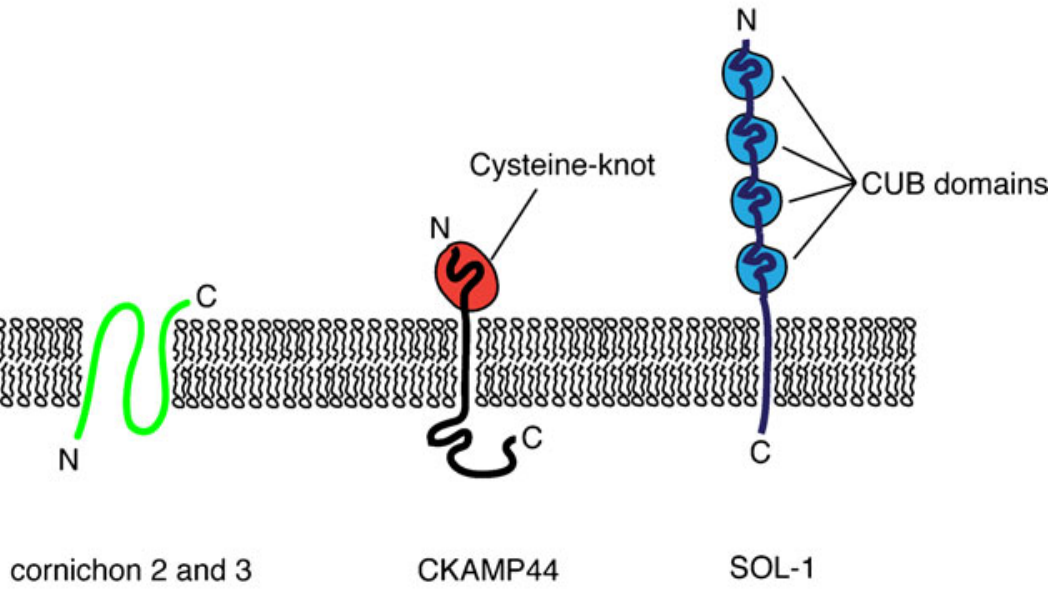

Fig. 1 AMPA-R and auxiliary subunits. a Primary structure of a subunit of AMPA-R. NTD N-terminal domain, $L B D$ ligand binding domain, $T M D$ transmembrane domain, $C T D$ C-terminal domain. The LBD is made of S1 and S2 subfragments. The TMD contains alphahelices M1-M4. The linkers between the domains are also indicated. b Domains of a subunit of AMPA-R. The large rectangle indicates the membrane. The NTD, LBD, TMD, and CTD are coded in the same color as in (a). c Tetrameric structure of the AMPA-R. In the tetramer, a pair of NTD dimer $\left(N T D_{2}\right)$ is located most distal from the membrane. A pair of LBD dimer $\left(L B D_{2}\right)$ forms the middle layer and

packing and a series of studies on the structure-function relationship of the receptor demonstrated that the dimeric organization of the LBDs seen in the crystal structure is physiologically relevant [51-57]. Because the mature AMPA-Rs are tetramers while the LBDs are dimers, it was proposed that the AMPA-Rs adopt a dimer-of-dimers global subunit arrangement. Subsequently, using constructs that have similar design principal as the original S1S2 the tetrameric TMD is embedded in the lipid bilayer. The organization of the four CTD $(4 x C T D)$ in the cytoplasm is currently not understood but speculated to be flexible. Each modular unit is color coded as in (a) and (b). d Negative stain single particle EM image of an AMPA-R made of homotetrameric GluA2 [23]. The relation between the known domains of the AMPA-R and the substructures of the EM image are indicated. e Auxiliary subunits of AMPA-Rs. The schematics of the membrane topology and domain organization of stargazin/TARP, cornichons, CKAMP44, and SOL-1 are shown

construct, the X-ray structures of the isolated LBDs of NMDA-Rs, kainate receptors, GluR0, and GluRdelta2 receptors were solved [58-64]. The design principle of the S1S2 construct was also applied to the LBD of the mGluR1 [65], whose primary structure is actually more homologous to the NTDs of the ionotropic glutamate receptors.

The first insights into the ultrastructure of the intact fulllength AMPA-Rs were provided by electron microscopy 
[66-69]. In 2001, the first negative stain single particle EM projection structures of the GluA2 tetramer expressed and purified from $\mathrm{Sf} 9$ cells were reported [68]. This study provided the overall dimensions of the particles (approximately $11 \times 14 \times 17 \mathrm{~nm}$ ) and the pseudo2 -fold symmetry of the receptor. The 3D EM density map of GluA2 tetramer expressed and purified from Sf9 cells demonstrated overall 2-fold symmetry of the receptor but consistency was not described with the known crystal structures [69]. The possible discrepancy between the EM structure and the crystal structures of the related domains prompted the need to accumulate more data in the field to understand the structure of the intact full-length AMPARs. In 2005, a method to purify homogeneous particles of native AMPA-Rs from rat brain was developed and the purified receptors were further analyzed using single particle EM [66]. At the resolution of about $30 \AA$, the cryo-negative stained single particle 3D EM structures of the native AMPA-R containing auxiliary subunits stargazin/TARP and the native AMPA-Rs without the stargazin/TARP were reported [66, 67] (Fig. 2). The EM structure of native AMPA-Rs purified from rat brain $[66,67]$ looked very different from those of GluR2 homotetramers expressed and purified from Sf9 insect cells [69, 70]. Of particular importance, however, is that the sizes and shapes of the individual globular densities observed in the EM density map of the native AMPA-Rs were consistent with those of the crystal structures of the GluA2 LBD and GluA2 NTD $[66,71]$. The structure also was consistent with the proposed dimer-of-dimers assembly of the subunits. The electron microscopy studies of native AMPA-Rs also revealed the global conformational changes of the receptor upon desensitization [66, 67] (Fig. 3). The detail of this study is discussed in the later section.
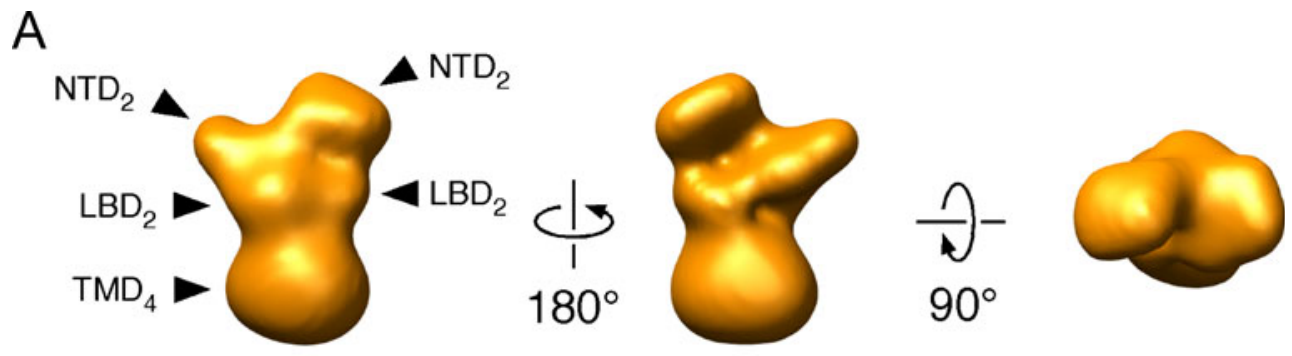

B
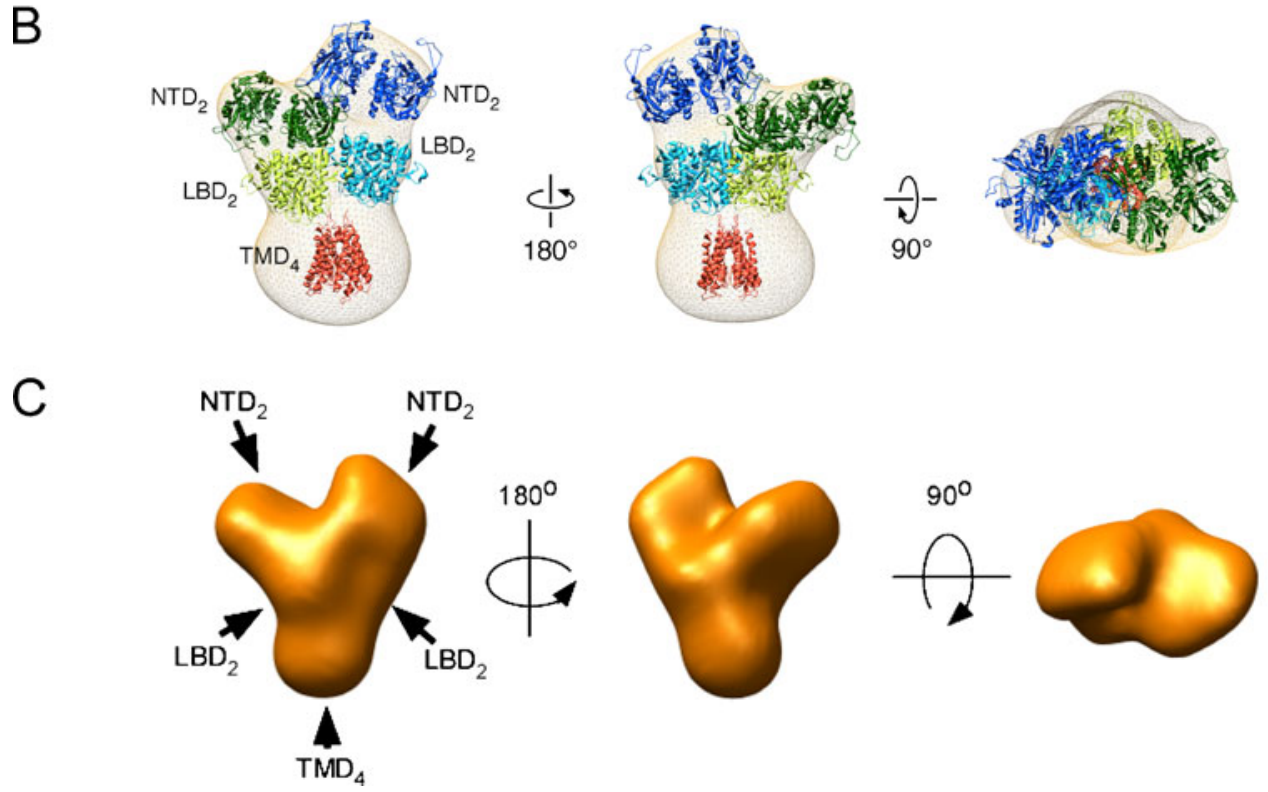

Fig. 2 Low-resolution 3D view of the native AMPA-R obtained by single particle EM. a Cryo-negative stain 3D EM density map of native AMPA-R containing stargazin/TARP at the resolution of around $30 \AA$. Three different views of the particles are shown. The domains that correspond to each globular substructure are shown. $N T D_{2}$ NTD dimer, $L B D_{2}$ LBD dimer, and $T M D_{4}$ TMD tetramer. b The placement of the crystal structures into the EM density map in (a). The crystal structures used are: extracellular domain of mGluR1 (PDB:1EWV, dark blue and dark green); ligand binding domain of

GluR2 (PDB:1LBC, light blue and light green), and transmembrane segment of KcsA (PDB:1BL8, red). c Cryo-negative stain 3D EM density map of native AMPA-R without stargazin/TARP at the resolution of around $30 \AA$. Three different views of the particles are shown. The domains that correspond to each globular substructure are indicated as in (a). The size of the TMD is significantly smaller than the structure shown in (a). The difference in the size of TMD accounts for the auxiliary subunits stargazin/TARP. The images were reproduced from $[66,67]$ 


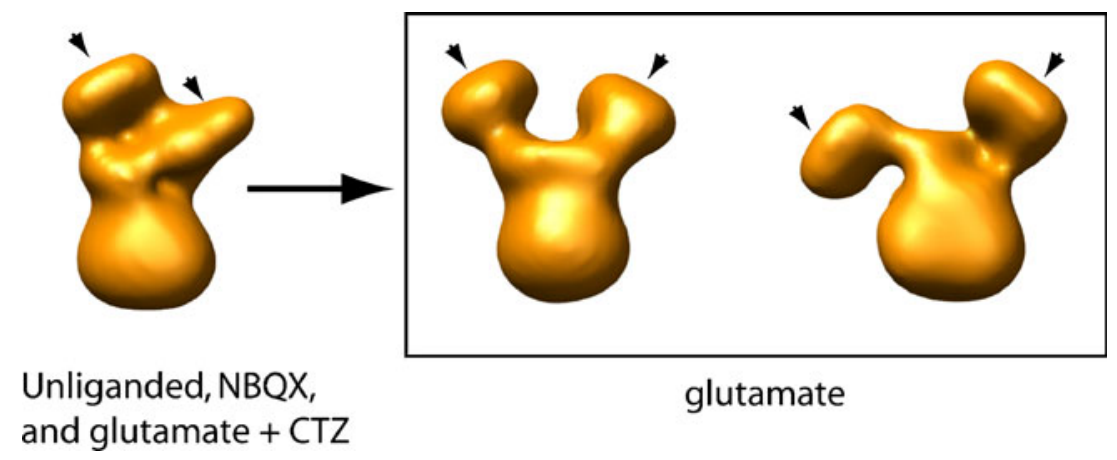

Fig. 3 Different conformations of native AMPA-R. The AMPA-R particles adopt different conformations in the presence of various drugs. Unliganded, NBQX $(30 \mu \mathrm{M})$ treated, and glutamate $(1 \mathrm{mM})+$ CTZ $(330 \mu \mathrm{M})$ treated particles, respectively, adopt conformation shown in left. In this conformation, the two NTD dimers are close to

It was not until 2009 that the crystal structures of isolated NTDs of the GluA2, GluK2, and GluN2B were solved [7174]. The expression of the NTDs required demanding systems that used eukaryotic hosts such as the HEK cells and the Sf9 cells. The NTD crystal structures of GluA2 and GluK2 were homodimeric, while the GluN2B NTD was monomeric. Interestingly, Aricescu's laboratory isolated tetrameric GluA2 NTD in solution and its crystal structure revealed a dimer-ofdimers arrangement of the NTDs [71]. Similar tetrameric arrangement of the GluA2 NTD was also observed in the crystal packing of GluA2 NTD from Gouaux's laboratory [72]. Furthermore, the global domain arrangement of the GluA2 NTD tetramer in these crystals was consistent with the NTDs in the cryo-negative stain EM density map of the native AMPA-R without the stargazin/TARPs [71].

An important breakthrough was the study on the crystal structure of the near-intact AMPA-R, the product of GluA2cryst construct, reported in December 2009 from Eric Gouaux's laboratory [75]. The X-ray crystallography powerfully resolved the atomic structures of the individual domains and the tetrameric assembly of the almost intact subunits of the antagonist bound AMPA-Rs. The structure at the high resolution proposed many important chemical mechanisms involved in the process of ligand binding, gating, desensitization, and modulation (discussed in the later sections). The arrangement of the NTDs in the GluA2cryst tetramer was consistent with the crystal structure of the tetramers formed of the isolated GluA2 NTD [71]. The overall domain arrangement of the X-ray structure was different but showed resemblance to the previous EM structures. With careful inspection and comparison, the two structures can be interpreted in a consistent logical framework, as described in detail in the later section (Fig. 4).

By controlling the timing of GluA2 expression using a DOX inducible expression system, a recent study showed that subunit dimers are the intermediate biosynthetic form of AMPA-Rs [23]. Comparison of the single particle EM each other. The structural difference between the three conditions was not detectable at the resolution of the study. Right box - particles that are treated with glutamate $(1 \mathrm{mM})$ adopt conformations in which the two NTD dimers are separated. Each NTD dimer is indicated by the short arrows. The images were reproduced from [66]

structures of the dimeric and the tetrameric AMPA-R revealed the possible gross conformational changes that occur during AMPA-R maturation. Furthermore, the separation of the LBDs is required for maturation. The study also proposed a model for the connection between the individual domain in the tetrameric AMPA-R. The detail of this study is discussed in the later section (Figs. 6 and 7).

One of the main reasons that the structural studies of intact glutamate receptors lagged behind compared to the acetylcholine receptors [76-79] is the lack of good biological specimens. Specifically, unlike the electric organs of the electric rays that are rich in homogeneous population of Ach receptors, there was no known biological specimen that has a high concentration of homogeneous glutamate receptors. The brain was obviously rich in glutamate receptors, but the receptors were not homogeneous enough to use without purification. The important biochemical breakthroughs were (1) the successful engineering, expression, and purification of the recombinant ligand binding domain (the S1S2 construct) [25], NTD [71, 72, 74], and the near full-length receptor (the GluA2cryst construct) [75] and (2) the development of the method to purify intact AMPA-Rs from the rat brain $[66,67]$. The former approach was used to crystallize the receptors for structural determination by X-ray crystallography, while the latter was used for structural determination by single particle electron microscopy.

\section{Biochemistry of Endogenous AMPA Receptors}

Detergent Extraction and Purification of Endogenous AMPA Receptors

The AMPA-Rs are known to be highly soluble when extracted from the brain membrane using mild detergents. "Mild detergents" means either zwitter ionic or non-ionic detergents with a large hydrophobic group. The choice of 

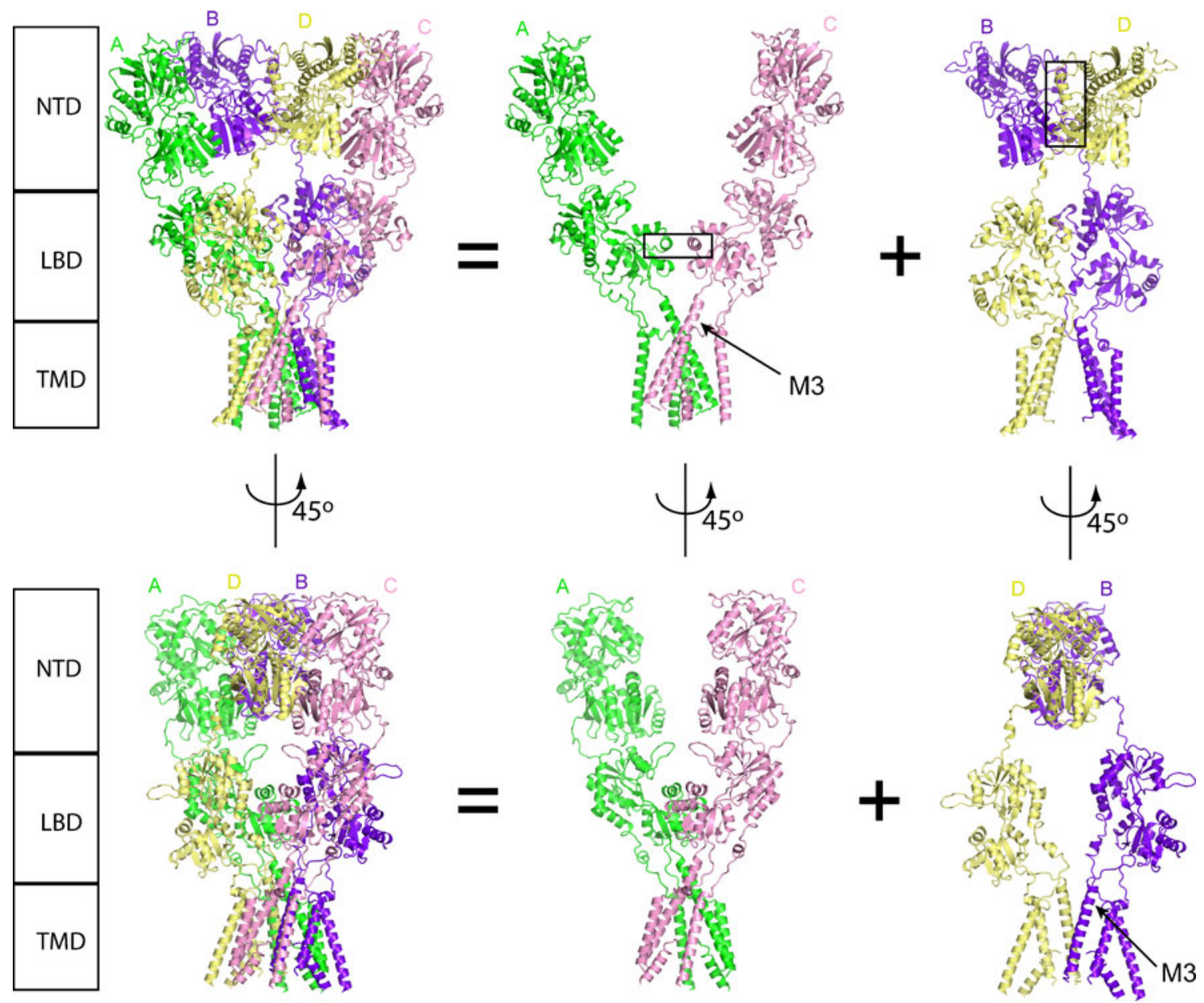

Fig. 4 Atomic view of the AMPA-R from the crystal structure of GluA2cryst. The crystal structure of GluR2cryst (PDB:3KG2) [75] viewed from two different angles. In each row, the tetramer is shown on the left. Four subunits are denoted as $A-D$, and each subunit is coded in different colors. The structures on the right side show only two subunits out of the four. Within each row, the sum of the two structures on the right corresponds to the tetrameric structure shown on the left. The structures in the second row are viewed after rotating each structure on the top by $45^{\circ}$ around the global axis perpendicular to the membrane. The locations of NTD, LBD, and TMD layers are indicated on the left end of each row. The M3 alpha-helices are

the detergent is critical in preserving intact tetrameric assembly of the AMPA-Rs. The detergent solubility of the brain AMPA-Rs was investigated by Blackstone and Huganir [80]. In their study, they solubilized the brain membrane using different detergents (Triton X-100, octyl$\beta$-D-glucopyranoside, digitonin, and CHAPS) and determined that a high yield of $\mathrm{H}^{3}$-AMPA binding activity was recovered from brain membrane extracted by $0.5 \%$ CHAPS.

Not every detergent can maintain the intact macromolecular assembly of the AMPA-R complexes. In fact, the spectrum of effective detergents is very limited. More specifically, solubilizing brain membrane with decylmaltoside $(0.6 \%)$, dodecylmaltoside $(0.1 \%)$, or octyl- $\beta$-D- indicated by the arrows. The subunits $A$ and $C$ have longer M3 helices and the LBDs of these two subunits form the inter-dimer contacts between the two dimeric NTDs (indicated as a black rectangle in the top middle structure). The subunits $B$ and $D$ have shorter M3 helices and the NTDs of these two subunits form the inter dimer contacts between the two dimeric NTDs (indicated as a black rectangle in the top right structure). The $A-B$ and $D-C$ are the pairs of subunits that form the NTD dimers, whereas $A-D$ and $B-C$ are the pairs that form the LBD dimers. The TMD has 4-fold symmetry made by all four subunits. The images were prepared using pyMOL

glucopyranoside $(0.3 \%)$ all resulted in recovery of particles with smaller molecular weights [67]. Investigation of these smaller particles by negative stain EM confirmed that these smaller particles adopt shapes that are distinct from the views of the tetrameric AMPA-R model. Interestingly, as described below in the section of recombinant GluA2 tetramers, the best choice of detergent varies between recombinant and native receptors. This may suggest that the stability in detergent is different between recombinant homotetramers and native heterotetramers. Alternatively, the composition of the surrounding lipids and the auxiliary subunits in each experimental system are different and confer distinct stability in different detergents. 
Immunoaffinity purification chromatography plays important roles in purifying AMPA-Rs from the brain [66, 67]. The anti-GluR2 (GluA2) C-terminal antibody has a very convenient characteristic of being able to efficiently release the bound antigen by competitive elution of the epitope peptide. Furthermore, the antibody affinity was high enough to enrich GluA2 subunit containing AMPA-Rs from the brain lysate and the peptide elution could detach all the receptors that were bound to the column. These advantages and the availability of reagents made AMPA-Rs a good target for purification among other glutamate receptors. Importantly, antibodies against other glutamate receptor subunits do not necessarily have such characteristics (unpublished observations).

The Proteins that Co-Purify with the Native AMPA-Rs

The AMPA-Rs in the brain interact with a variety of proteins, and thus when one purifies AMPA-Rs from brain tissue many proteins co-purify with the receptors. Precisely identifying the proteome of the AMPA- $R$ is itself an important area of research that may lead to identifying the novel molecular mechanism of AMPA-R function and modulation.

Most of the initial studies that identified protein interactors of AMPA-Rs used yeast two-hybrid screening. In this approach, cytoplasmic fragments of the AMPA-R subunits were used as a bait to screen a brain cDNA library to search for cDNAs that encode interacting partners. This approach identified many C-terminal interactors, such as GRIP [81], PICK1 [82], NSF [83-85], AP-2 [86], protein 4.1 [87], RIL [88], and IQGAP [89]. Based on drawing an analogy to the interaction between GluN2 and PSD-95, the interaction between GluA1 and SAP97 was identified by directly testing the interaction [90]. The C-terminus of AMPA-R subunits is also a substrate for kinases that regulate receptor function [91, 92]. A subset of these proteins was identified by LC/MS/MS when GluA2 containing AMPA-Rs were purified from brain [45, 46, $66,93]$. The experimental conditions used to biochemically isolate the receptors were suboptimal to extract some of the membrane complexes. Furthermore, the PDZ domains and their ligands interact at dissociation constants [94] that will not allow tight association, and thus may not be stable enough to co-purify large quantities.

A series of data demonstrated the functional significance of stargazin and its homologues, the TARPs in AMPA-R trafficking and channel modulation [44, 95]. Purification of native AMPA-Rs from brain subsequently confirmed the presence of stargazin/TARP [66, 96]. Further experiments have identified novel binding partners in the membrane during the past few years. Chemical crosslinking followed by immunoprecipitation identified $\mathrm{N}$-cadherin as interactor
[93]. More intensive purifications and analyses have identified cornichons [45] and CKAMP44 (also known as shisa 9) [46]. Importantly, the latter two proteins co-purify with native AMPA-Rs without using chemical crosslinkers in stark contrast to the interaction between the GluA2 NTD and N-cadherin. The cornichons and CKAMP44 are transmembrane proteins that belong to completely different families. From a different line of research, conotoxin conitok-itok was identified that is homologous to CKAMP44/ shisha9 [97]. It will be interesting to see if shisa 7, a homologue of shisa 9 in the rat genome, also has similar function to CKAMP44/shisa9.

Biochemical manipulations are available that can remove auxiliary subunits from the AMPA-Rs. For example, purifying the AMPA-Rs with CHAPS and exchanging the detergent into DDM using gel filtration was reported as a manipulation that can remove the stargazin/TARPs from the tetrameric channel core $[66,67]$. Functional interaction between stargazin/TARPs and AMPA-Rs can decrease in the presence of a high concentration of glutamate [98]. Consistently, for receptors that were solubilized in Triton $\mathrm{X}-100$, application of high concentration of glutamate to the receptors also dissociate stargazin/TARPs from AMPARs [99]. However, glutamate induced dissociation of stargazin/TARPs was not observed for those receptors solubilized in CHAPS [66]. The detailed biochemical properties of the interactions between AMPA-Rs and the auxiliary subunits (cornichons and CKAMP44) that were identified recently are still unknown.

The majority of the endogenous cytosolic interactors of AMPA-Rs can be removed by washing the membrane with caotropic salts [66]. This manipulation enriches for the integral membrane proteins. Highly pure native AMPA-Rs were obtained from P2 brain membranes that were washed with KI and urea. Treating synaptosome enriched P2 membrane with $1 \mathrm{M} \mathrm{KI}$ and $4 \mathrm{M}$ urea does not affect the conformation of the AMPA-Rs purified from rat brain. We have compared the structures of the AMPA-Rs that were purified from $\mathrm{P} 2$ membranes that were washed with $1 \mathrm{M} \mathrm{KI}$ followed by $4 \mathrm{M}$ urea and those that were not washed (unpublished observation). The EM structures of the AMPA-Rs obtained from both preparations were indistinguishable. A recent publication claims that urea destabilizes the native conformation of AMPA-Rs [70]. However, in [70], the authors omit the $1 \mathrm{M} \mathrm{KI}$ wash and omit adding $30 \mu \mathrm{M}$ of AMPA-R specific full-antagonist NBQX during purification. To our knowledge, the inclusion of the NBQX is critical to obtain a structurally homogeneous preparation of AMPA-Rs. Therefore, the reported urea-induced destabilization of the AMPA-R is a phenomenon observed in a very specific experimental system. It is important to note that $4 \mathrm{M}$ urea wash of the membrane is an effective approach in improving the purity and quality of other 
membrane proteins, such as gap junction connexins and aquaporins [100-102]. In addition, vesicles that were washed with KI maintain their ability to bind to molecular motors and thus can be used for in vitro motility assays, suggesting that motor acceptors on the vesicles are unaffected by the KI wash [103].

Controlling the stability of proteins complexes formed between AMPA-Rs and the individual auxiliary subunit will be important in determining the structural basis and regulation of their function. With an accurate understanding of the mechanism of endogenous modulators, new methods of manipulation can be discovered. This may ultimately lead to developing therapeutic means for various disorders affected by the dysfunction of AMPA-Rs.

\section{Single Particle EM Studies of Brain-Derived AMPA-Rs}

AMPA-Rs purified from the rat brain were studied using cryo-negative staining and single particle electron microscopy [66, 67]. Native AMPA-Rs purified from brain were cryo-protected using glycerol, attached to the surface of a thin carbon membrane, negative stained using $0.7 \%$ uranyl formate, and quickly plunged into liquid nitrogen to achieve vitrification of the specimen [104]. Cryoprotection and quick freezing enable ultrastructural preservation of the negative stained specimen. The frozen grid was observed under liquid nitrogen temperature in the transmission electron microscope using low dose procedure (below 20 electron $/ \AA^{2}$ ) to minimize radiation damage caused by the electron beam. The advantage of cryonegative stain over the conventional negative stain is the capability to image hydrated macromolecules maintaining native structure. Cryo-negative staining was also used in the study of potassium channel [105].

The global domain arrangement of the native AMPA-R is shown in Fig. 2. The EM density map was interpreted in two steps; first by identifying the NTD and the TMD using Fab labeling, and then by placing the known crystal structures of the individual domains. The two dimers of the NTDs are located at the top of the particles and have the appearance of two elongated densities. The Fab fragment that recognizes the NTD binds to these densities, and thus each of these densities was interpreted as one NTD dimer. Because the Fab that recognizes the C-terminus of the receptor consistently labeled the bottom part of the particles, the bottom density was interpreted as the TMD.

The sizes and shapes of the EM densities corresponding to the two NTD dimers were consistent with the crystal structure of the dimeric mGluR1 LBD [65] (Fig. 2b). (When the EM structure was published, the crystal structures of the GluA2 NTD were not available. The mGluR1 LBD is a close homologue of GluA2 NTD whose crystal structure was available at the time.) Later it was shown that the crystal structure of the GluA2 NTD tetramers could also be placed into these densities [71]. The existence of two dimeric NTDs in the structure was consistent with the proposed dimer-of-dimers organization. The densities immediately below the two NTD dimers were consistent with size and shapes of the two dimeric crystal structures of the isolated LBD dimers [51]. The density of the TMD, however, was larger than what would be expected if the structure was made only by the four GluA subunits. The LC/MS/MS identified that stargazin/TARPs co-purified with the native AMPA-Rs. Immunolabeling of the particles with Fab fragments that specifically recognize the C-terminus of the stargazin/TARPs consistently labeled the bottom part of the transmembrane density, indicating that the large transmembrane density contained the stargazin/TARPs. Consistently, when the particles were washed with decylmaltoside or dodecylmaltoside, the auxiliary stargazin/TARPs were removed as judged by Western blotting, and the size of the transmembrane density decreased (compare the TMD of Fig. 2a, c). This indicates that the interaction between stargazin/TARPs and AMPA$\mathrm{Rs}$ is sensitive to detergents. The interpretation of the EM density map provided a conceptual link between various structural and molecular data in the field.

Another important finding was the glutamate-induced conformational change of the NTD dimers, more specifically a lateral displacement of the two NTD dimers (Fig. 3). The conformational change was blocked by the antagonist NBQX or the inhibitor of desensitization CTZ, indicating that the lateral displacement of the NTD dimers is related to desensitization. This concept was particularly novel at the time because the lateral movement of the NTD dimers was unpredictable from the glutamate-induced clamshell closure observed in the crystal structures of the isolated LBD dimers. Recently, the crystal structure of GluA2cryst together with the crystal structure of the isolated LBD of the S729C mutant that adopts the "desensitized-like" conformation [52] predicted a mandatory displacement of the NTD dimers during desensitization [75], confirming and extending the desensitization-related lateral displacement of the NTD dimers proposed from the earlier EM studies.

Due to the limited resolution of the EM density map, many questions remained unanswered. For example, how individual domains are connected within the tetrameric assembly was not resolved. Other than the gross conformational change related to desensitization, the detailed conformational changes and mechanisms of gating were not clear. It was also unclear whether the conformational changes of AMPA-Rs solubilized in detergent faithfully represent the conformational changes of the receptors in the membrane. As discussed above, 
however, the recent high-resolution X-ray structure also predicts similar conformational changes [75]. The magnitude of the lateral displacement of the NTD dimers was greater in the EM study than was predicted from the X-ray study. Although it may not completely explain the cause of the difference, one likely source is the different length of the linker connecting the NTD and the LBD. In the GluA2cryst, NTD-LBD linker is significantly shorter than the wild-type sequence. The EM structure was obtained from images of particles attached to the carbon membrane in the presence of negative stain $(0.7 \%$ uranyl formate), and thus may have caused small distortions to the global structure. However, in many cases the negative stain EM structure provides a good approximation of the actual macromolecular structure [104, 106].

\section{Recombinant Expression of Homotetrameric AMPA Receptors}

Because AMPA-Rs from brain are molecularly heterogeneous, they are not suited for detailed structural studies. Expression and purification of membrane proteins in general are challenging. Complications arise for many reasons that are still incompletely understood. A recombinant membrane protein must express well, fold correctly, and not be toxic to the host cell to be useful for biochemical studies. Modest expression facilitates correct folding of the protein [107-109]. Recombinant AMPA-Rs have advantages over native receptors. Specifically, subunit composition can be controlled and genetically modified receptors can be generated to study structure-function relationships. All of the expression systems reported so far use eukaryotic expression systems in order to express AMPA-Rs. Moreover, most of the studies are done using the homotetramers of the GluA2 subunit.

Homotetrameric GluA2 Expressed and Purified from HEK Cells

Studies have reported stable mammalian cell lines that express functional AMPA-R subunits [110, 111]. These stable cell lines were developed to study channel function using electrophysiology or to conduct drug screening, and thus purification tags are not included in the receptor subunits. To purify AMPA-Rs from recombinant sources, the expression must be high enough so that the cell culture can be done at a reasonable scale. However, when expressed at high levels, many of the glutamate receptor subunits are toxic to the cells because there is glutamate in the media (more specifically in the FBS) that can activate the receptors. Furthermore, too high expression of AMPA$\mathrm{R}$ subunit causes protein aggregation. For instance, tran- sient expression using plasmid transfection gave good yield but the majority of the AMPA-Rs aggregated and elute in the void fraction in the gel filtration chromatography [23].

HEK cells are a useful host cell line for membrane protein expression $[112,113]$. The GluA2 homotetramers assemble without aggregation or misfolding when expressed at a modest level using stable HEK cell lines. Based on the yield of purification, it was estimated that at least 15,000 20,000 GluA2 tetramers are expressed per cell. No auxiliary stargazin/TARP subunits were detected in the purified recombinant GluA2 fraction when examined by Western blotting using a pan-TARP antibody and by protein identification using liquid chromatography followed by tandem mass spectroscopy (LC/MS/MS) [23]. This suggests negligible contribution of HEK cell-derived stargazin/ TARPs during AMPA-R assembly in this system. It is possible, however, that endogenous g-7 [114] that is not immunoreactive with pan-TARP antibody may be present in HEK cells. It is not clear if any endogenous cornichon homologues and CKAMP44/Shisa9 homologues are expressed in HEK cells.

Shanks et al. [23] systematically compared the structures of GluA2 tetramer that were expressed constitutively in HEK cells and GnTI(-) HEK cells. Recombinant GluA2-FLAG was purified from cellular membrane that was solubilized using $0.25 \%$ dodecylmaltoside in the presence of $30 \mu \mathrm{M}$ NBQX. Immunoaffinity purification using anti-FLAG M2 column was followed by gel filtration using a Superdex 200 column. Interestingly, CHAPS, which was selected as a good detergent to extract AMPA-Rs from brain, did not preserve the ultrastructure of the tetrameric GluA2 from HEK cells (unpublished observation). They conclude that the projection structures of each of these receptors are indistinguishable from the native AMPA-Rs void of stargazin/TARPs purified from brain at the resolution of around $20 \AA$.

Homotetramers of GluA2cryst Expressed and Purified from Sf9 Cells

The Sf9 insect cells were used as host to express recombinant AMPA-R subunits [75, 115-117]. Among these, the GluA2flip splice variant was developed in Eric Gouaux's laboratory to maximize the expression and stability of the protein for X-ray crystallographic studies of AMPA-R structure. The resulting GluA2cryst construct contains various small modifications throughout the receptor, is capable of gating in the presence of CTZ, and expresses in Sf9 insect cells at a quantity high enough to conduct crystallography. It has been shown that the AMPA-Rs expressed in Sf9 cells are functional [115, 116]. The wildtype GluA2 homotetramers conduct very small current [40], but the GluA2cryst conducts even smaller current compared to the wild-type GluA2 (supplementary figure of [75]). 
However, GluR2cryst and wild-type GluA2 have similar levels of glutamate-induced currents in the presence of CTZ (supplementary figure of [75]).

The challenge of obtaining high-quality AMPA-Rs for structural studies can be understood when we look at the details of the construct engineering reported in [75]. First, gel filtration was used to identify GluA2flip as the subunit that expresses and folds the best in Sf9 cells. GluA2flip was further engineered as follows: approximately 35 amino acids of the cytoplasmic C-terminal domain were deleted. Six out of 17 amino acids were deleted from the linker that connects the NTD and the LBD. Two N-linked glycosylation sites within the linker were mutated such that sugar cannot be added. Nine amino acids in the NTD and the LBD were mutated. Two residues in the transmembrane segments were also mutated. The residue in the Q/R RNA editing site was $\mathrm{Q}$, the non-edited form. A His tag was placed after the M4 to facilitate purification. The GluR2cryst was extracted from Sf9 cells using $40 \mathrm{mM}$ dodecylmaltoside. The purification using cobalt-charged chelating sepharose was followed by gel filtration. During the gel filtration, the detergent was exchanged to $1 \mathrm{mM}$ undecylmaltoside and $0.01 \mathrm{mg} / \mathrm{ml}$ phospholipids (a mixture of POPC/POPE/POPG-3:1:1) was included.

\section{The Crystal Structure of the Near-Intact AMPA-R made of GluR2cryst Homotetramer}

The GluR2cryst homotetramer in complex with the competitive antagonist ZK200775 was crystallized and its structure was determined at 3.6- $\AA$ resolution [75]. The structure represents the closed state of the channel. The global architecture can be subdivided into three layers: the NTD layer, LBD layer, and the transmembrane (or channel pore) layer (Fig. 4). The NTD layer and the LBD layer are each formed by a pair of NTD dimers and a pair of LBD dimers, respectively. The protomers within the NTD and LBD dimers are related to each other by the 2-fold axis perpendicular to the membrane plane. Using the same symmetry axis, the TMD has approximately 4-fold rotational symmetry, whereas the architecture of the top part of the channel pore with the linker sequence that connects to the LBD has a 2 -fold rotational symmetry. The relative arrangement of the two NTD dimers in the GluA2cryst was very similar to what was observed in the crystal structure of the tetrameric GluA2-NTD [71, 72]. The interface between the two NTD dimers was made by the inner two subunits that are closer to the global 2-fold axis. The structures of each NTD dimer were indistinguishable from what was observed in the dimeric crystal structures of the NTD. The C-termini of the NTDs connect to the N-termini of the LBDs through the linker sequence.
In this connection, the pair of subunits that form single NTD dimer is not the pair of subunits that form the LBD dimers. The structures of the LBD dimers were very similar to the previously reported structure except that the antagonist ZK200775 locked the pocket of the clamshelllike structure of the LBD into a further extended conformation than the other competitive antagonists. A novel small interface between the two LBD dimers was identified and was predicted to form a weak dimer-dimer interaction.

The domain arrangement in wild-type GluA2 was proposed by extending the models from the GluA2cryst structure. Cysteine residues were introduced into the wildtype GluA2 sequence at locations that were predicted to make close inter-domain contacts, specifically the interNTD dimer contact point (V209C), inter-LBD dimer contact point (K663C and $\mathrm{I} 664 \mathrm{C}$ ), and the inter-TMD contact point (M629C). When expressed in HEK cells, the mutant subunits formed disulfide bonds, indicating that the residues mutated to cysteines were within close proximity.

The architecture of the transmembrane domain of the GluR2cryst contained many of the concepts gained from the previous studies that proposed the topology of the transmembrane segments $[26,118]$. Specifically, the M1, 3, and 4 form alpha-helices and span the membrane and the M2 is part of a reentrant loop. The structure around M2 that corresponds to the ion selectivity filter in the potassium channel [119] was largely disordered in the crystal structure of GluA2cryst and its structure remained unclear. The channel pore was lined by the M3 helices. The alphahelices of M3 cross near the outer side of the membrane and form a narrow constraint creating an occlusion of the putative ion permeation pathway. The region around the crossing of the M3 helices is made of the highly conserved amino acid sequence among the glutamate receptors (SYTANLAAF) that is mutated in the lurcher mutant mice [120]. The pore diameter of the ion permeation pathway was the narrowest where the conserved amino acids SYTANLAAF were located in the GluA2cryst structure. M4 is not part of the central ion permeable pore but an extensive interaction between the M4 helix and the others were detected.

The core gating machinery that has 2 -fold symmetry is made of the region between the LBD and M3. The connection between the LBD and the M3 contributes largely to the transition of symmetry between the LBD layer (2-fold rotational symmetry) and the transmembrane layer (4-fold rotational symmetry). The lengths of the M3 alpha-helices are not equal in all four subunits. According to their length, the four M3s can be subdivided into two pairs. The pairs are defined such that within each pair the two M3s have a 2-fold rotational symmetry around the global rotational axis perpendicular to the membrane plane. 
In other words, if one draws a square by connecting the four M3s that appear in a cross section tangent to the membrane plane, the two M3s that are located diagonally form one pair. The length of the M3 in one of the pairs is longer than the other. The shorter M3s are connected to the two LBDs that do not form the inter-LBD dimer interface. Because the ends of these two LBDs that connect to the shorter M3s are located farther away from the channel pore, these M3-LBD linkers are more extended compared to the other two M3-LBD linkers that connect the LBDs with the longer M3s. Consequently, the two LBDs that form the interface between the two LBD dimers (Fig. 4, top middle structure, rectangle) are derived from the two subunits that adopt the longer M3 helices and the M3LBD connection in these subunits are shorter. In relation to the NTDs, the subunits that adopt the shorter M3 are the same subunits as those that contribute to forming the interface between the two NTD dimers (Fig. 4, top right structure, rectangle). When the polypeptides of an individual subunit are traced carefully, it is immediately recognized that each subunit contributes to the overall tetrameric structure in either one of the two modes (in Fig. 4, subunits A and C are one mode, whereas $\mathrm{B}$ and $\mathrm{D}$ are another).

Insights into the mechanism of gating were gained from the architecture of the channel core and the geometrical arrangements of the linkers connecting the membrane spanning segment and the LBD. The displacement of the M3 helices that form the narrow constriction of the ion permeable path will be necessary for gating. The crystal structure of the GluA2cryst predicts that the shorter M3 alpha-helices will undergo larger displacement upon the glutamate-induced closure of the clamshell-like LBDs. Conversely, the longer M3 alpha-helices will have a smaller degree of displacement and thus may contribute less to the gating. In this model, the pair of LBDs that are connected to the longer and shorter M3s, respectively, contributes differently to the gating. Based on the global domain arrangements of the LBD and the cysteine crosslinking experiments, it was suggested that in the NMDA-Rs the two GluN1-derived LBDs form the interface between the two LBD dimers and thus connect to the longer M3 alphahelices. GluN1 is the glycine binding subunit of NMDARs. Because the GluA2cryst structure predicts that the LBDs connecting to the longer M3 contribute less to gating, a similar principal may explain why glycine contributes less to channel gating in the absence of glutamate.

Insights into the mechanism of desensitization were gained by comparing the crystal structure of GluAcryst and mutant LBD carrying the S729C mutation, a mutant that locks the LBD in a conformation that mimics the desensitized state [52]. The LBD clamshell is made of two lobes denoted as D1 and D2 lobes [25]. The D2 lobe is the lower lobe of the LBD clamshell that is closer to the membrane. The D2 lobes of the GluA2cryst in complex with the competitive antagonist ZK200775 superimpose well with the D2 lobes of LBD S729C mutant in complex with glutamate. The clamshell of the LBD S729C is closed by glutamate but the D2 lobes are separated in the same way as the LBDs in the GluA2cryst whose clamshell is open and ion channel is closed. This observation and the results from previous studies [52, 57] collectively suggest that desensitization results from the rupture of the LBD dimer that is made by the D1 lobes. Importantly, the GluA2cryst structure predicts that when the rupture of the D1 lobes happens during desensitization, the NTD together with the NTDLBD linker must move. More precisely, during desensitization, it was predicted that the distances between and within the NTD dimers must change. This prediction is also supported by the previous single particle EM study that experimentally demonstrated the distinct conformation of the NTD dimers in the presence or absence of glutamate and CTZ [66], and the electrophysiological study that demonstrates the importance during gating of multimerization state of the NTDs [121]. It is well known that the binding of $\mathrm{Zn}^{2+}$ and ifenprodil to the NTDs can modulate channel function of the NMDA-Rs [122-126]. By inverting the cause and consequence, the predicted mandatory movement of the NTDs upon desensitization is also consistent with the channel-modulating function of the NTDs in NMDA-Rs.

The crystal structure of GluA2cryst raises many new questions. The current structure of GluA2cryst represents a channel-blocked structure. Different conductive states have been reported for AMPA-Rs, suggesting the existence of more than one conformation when the channel is open [127]. Understanding the architecture of the different gating states will be the next challenge. As described in the earlier sections, gating of AMPA-Rs is modulated by auxiliary subunits. Which part of the AMPA-Rs is involved in the functional modulation by the auxiliary subunits such as stargazin/TARPs? The cytoplasmic C-terminus of the stargazin/TARPs is critical for modulating AMPA-R gating $[99,128]$, and thus any potions of the AMPA-R that are exposed to the cytoplasm are candidate interacting targets of stargazin/TARPs. In the GluA2cryst structure, however, the cytoplasmic C-terminal and part of the M2 reentrant loop are unresolved. Functional interactions exist between stargazin/TARPs and the residues in the narrow constriction of the AMPA-Rs [129]. The Q/R editing site located near the M2 is critical for the polyamine block of the AMPA-Rs [130]. The polyamine block of AMPA-Rs is also modulated by stargazin/TARPs [131]. Collectively, the opening of the pore on the cytoplasmic side is the likely candidate for the cytoplasmic interaction between stargazin and AMPA-Rs. 
The extracellular loops of stargazin/TARPs also participate in channel modulation [132]. The structural and biochemical data that support the complex mechanisms of modulation remain to be seen.

The structure of the GluA2cryst provided mechanistic interpretation to various experimental observations made on the structure-function relationship of the glutamate receptors. Many principles that govern the assembly and architecture of the GluR2cryst are likely extendable to other glutamate receptors. However, the structure and mechanism of the NTDs of the NMDA-Rs are suggested to be different from AMPA-Rs [133]. The NMDA-Rs are obligate heterotetramers that require the essential subunit GluN1. The crystal structure of the heterodimer formed of the LBDs of GluN1 and GluN2A together with the cysteine crosslinking study (E699C) of the GluN1 subunit suggests that, at the LBD level, the NMDA-Rs are assembled as a dimer of heterodimeric LBDs [59]. In contrast, currently there is no structural evidence that supports that the arrangement of the NTDs in the NMDARs follows the same principle as the AMPA-Rs. However, electrophysiological recordings from GluN2 subunits carrying mutation in the NTD suggest a model in which NTDs of GluN1 and GluN2 heterodimerize [134]. The affinity of the NTD dimer in kainate receptors is much lower than that of the AMPA-Rs [74]. If the affinity between the NTD dimer is lower in non-AMPA-type glutamate receptors, it is possible that depending on the conformational state and the phase of the assembly process the domain arrangement of the NTDs will dynamically change. In this view, the proposed domain arrangements in the NMDA-Rs may represent one state of the receptor and the mechanism around the NTDs will require further experimental characterization.

\section{Comparison of the Global Domain Arrangements of Brain AMPA-Rs and GluA2cryst Homotetramers}

The structural data of a molecule obtained using single particle EM and X-ray crystallography provide important overlapping and non-overlapping information [135]. A quantitative comparison between the EM density map and X-ray crystal structure can potentially identify sub-structures that are more flexible in solution, providing dynamic information about the molecule. As discussed above, the crystal structure of the GluA2cryst at the resolution of $3.6 \AA$ contains a considerable amount of detailed ultrastructural information about the AMPA-R [75]. Since the resolution of the EM structure of the native brain AMPA-Rs is at around $30 \AA[66,67]$, the crystal structure and the EM structure can only be compared at the level of the global domain arrangements. Interestingly, the global domain arrangements of the two structures are different. However, they are very much related.
The size and shape of the globular features seen in the EM density map were consistent with the known crystal structures of the related domains that were in the PDB. The crystal structure of the GluA2 NTD tetramer can be placed into the densities corresponding to the NTDs of the EM structure of native AMPA-R void of stargazin/TARPs [71]. The consistency between the crystal structure of the tetrameric GluA2 NTD and the low-resolution EM density map suggested that the inter-domain contacts seen in the crystal may be preserved in the full-length tetrameric receptor. The arrangements of the two NTD dimers in the crystal structure of the tetrameric GluA2 NTD [71] and the crystal structure of the tetrameric GluA2cryst [75] are indistinguishable, and thus the global arrangements of the NTDs in the GluA2cryst tetramer are in agreement with the low-resolution EM map (Fig. 5b). However, when compared side by side, it is immediately recognized that the EM structure is shorter than the GluR2cryst structure (Fig. 5a). The densities that correspond to the NTD dimer in the EM structure are tilted in one direction, whereas in the X-ray structure they are standing upright (Fig. 5a; the pivot axis of the tilt is indicated by the red arrows). The difference in the arrangements of the NTDs in the two structures contributes to the different heights and the difference in the overall symmetry (Fig. 5c). This tilt is the major cause of asymmetry that was observed in the EM structure. The linker that connects the LBD and the NTD in GluR2cryst is engineered such that it is six amino acids shorter and two predicted glycosylation sites [26, 136] are removed. Sobolevsky et al. [75] reported that these modifications were necessary to obtain crystals. Proteins with flexible conformation are more difficult to crystallize, and thus it makes sense if the linker that connects the LBD and NTD is flexible in the native AMPA-Rs that have a longer glycosylated linker. But simplifying the linker would reduce the structural complexity and conformational variety intrinsic to the NTD-LBD connection. Consistently, the NTD dimers were arranged in a variety of angles relative to the LBDs in the projection structures of the negative stained EM images of the native AMPA-Rs from brain [66, 67].

The NTDs of the AMPA-R bind to the cell adhesion molecule N-cadherin [93] and also to Narp and NP1 that have synapse-inducing function [137, 138]. These interactions are part of larger trans-synaptic protein networks in the synaptic cleft. The pre- and post-synaptic membranes are dynamic and accordingly the synaptic cleft is subject to structural plasticity $[139,140]$. Furthermore, recent studies have shown that rapid lateral movements of the AMPA-Rs along the plasma membrane are critical for synaptic plasticity [141]. The flexibility between the NTD and the LBD may play an important role in accommodating the dynamic capacity of the protein networks in the synaptic cleft. 

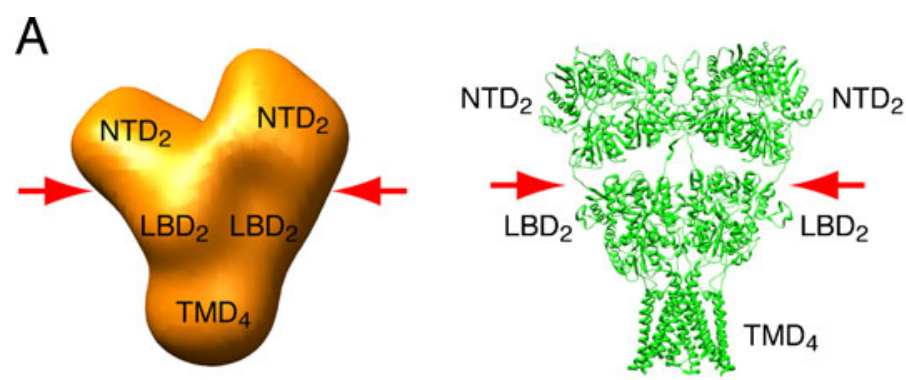

B
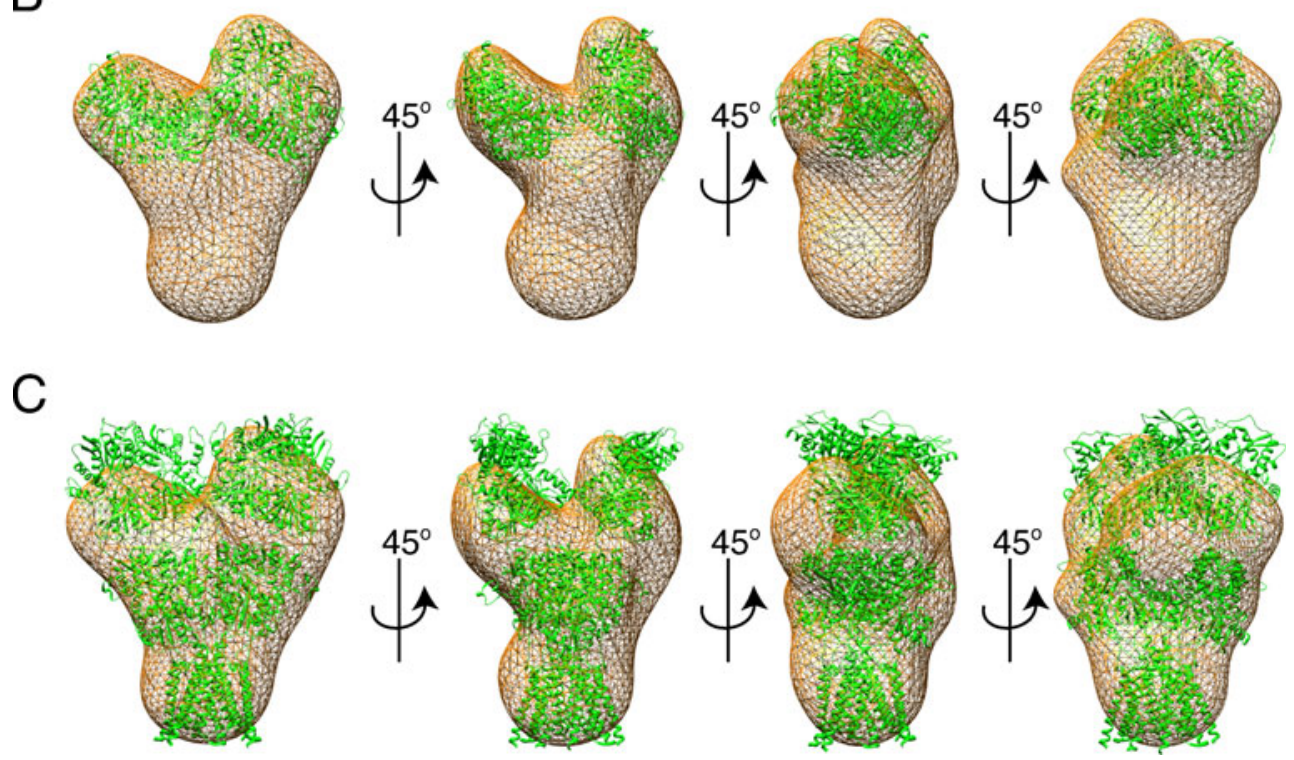

Fig. 5 The relationship between the EM and crystal structure of AMPA-R. a The cryo-negative stain EM structure (left) and the crystal structure of tetrameric GluA2cryst (PDB:3KG2) are shown at the same scale. Comparison of the two structures (as shown below in $\mathbf{b}$ and c) suggests that the NTD-LBD linker is flexible (see text for detail). The red arrows indicate the pivot points that locate the positions of the linkers that connect the NTD and LBD. b The NTD tetramer from the crystal structure of GluR2cryst (green) was placed into the EM density map of the native AMPA-R shown in (a) (represented here in mesh). Four different views are shown. The size

In conclusion, the early cryo-negative stain lowresolution density map provided the first ultrastructural information related to the global domain arrangement of the native AMPA-Rs. The extensive detail of the inter-domain contacts in the AMPA-Rs was revealed by the crystal structure of the tetrameric GluAcryst. However, because the linker between the LBD and the NTD was significantly engineered, there is a possibility that some functionally relevant structural information around the NTDs may not be contained in the GluR2cryst crystal structure. The current atomic structure of the GluR2cryst bound to competitive antagonist represents a blocked channel state. The single particle EM analysis revealed a difference in global conformation between the native AMPA-Rs that were treated with glutamate and glutamate + CTZ, indicating that lateral movement of the NTD dimers are and shape of the NTD density in the EM map is consistent with the dimer-of-dimers organization of the NTDs in the crystal structure of GluA2cryst. However, in order to place the NTD crystal into the EM density map, the crystal needs to be displaced and tilted along the pivot axis shown in (a). c The crystal structure of GluR2cryst (green) was placed into the EM density map of the native AMPA-R shown in (a) (represented here in mesh). Four different views are shown. The arrangements of the NTDs relative to the rest of the structure are the main differences between the global domain arrangements between the two structures. The images were produced using UCSF Chimera

related to desensitization. The mandatory movement of the NTD dimers was also predicted by the crystal structure of the GluA2cryst.

\section{Mechanism of Subunit Assembly of AMPA-Rs}

The subunit composition of the AMPA-Rs including the composition of the auxiliary subunits determine the biophysical properties of the ion channel and also affect the rules that govern receptor localization and trafficking [27, 142-145]. The molecular variety of the native AMPA-R complex is now known to be very complex because of many auxiliary subunits, including stargazin/ TARPs, cornichon, and CKAMP44 [47]. The dynamic changes of the AMPA-R localization and channel properties 
are source of modulations of synaptic transmission at the excitatory synapses and thus represent some underlying molecular mechanisms for synaptic plasticity. Interestingly, evidence suggests that the molecular composition of AMPARs can change in response to activity [98, 146, 147]. Recent studies also suggest that glutamate and RNA editing regulates the assembly process of AMPA-Rs [142, 148]. This indicates that subunit assembly is a new addition to known mechanisms modulating AMPA-R function and localization. Subunit assembly is an important process during AMPA-R trafficking, but the molecular process remained poorly characterized.

The trafficking pathway of AMPA-Rs consists of multiple steps [28] (Fig. 6). AMPA-Rs are synthesized as monomers in the ER and inserted into the ER membrane where they assemble into tetramers. The tetrameric AMPA-Rs continue their journey from the ER to the Golgi and exit the transGolgi network as part of trafficking vesicles. After reaching the cell surface, AMPA-Rs interact with a variety of scaffold proteins that facilitate synaptic localization of the receptors $[90,149,150]$. AMPA-Rs are also recycled and move back and forth between endosomes and the synapse [145, 151].

The ER is the site of synthesis of various membrane proteins. The ER actively facilitates the folding of membrane proteins and their exit from the ER in the form of trafficking vesicles [152]. The folding process is assisted by molecular chaperones including the members of the classical Hsp 70, Hsp 40, and Hsp 90 protein families. The assembled membrane proteins are incorporated into budding vesicles that are coated with COPII coat protein and further exported from the ER in trafficking vesicles [153-155]. When unfolded or misfolded proteins accumulate in the ER, the unfolded protein response (UPR) signals are triggered. For example, the transmembrane transcription factor ATF6 mediates the UPR by upregulating ER-specific chaperones including BiP and GRP94 [156]. UPR also attenuates transcription by activating ER resident kinases PERK and IRE1 [157]. Misfolded proteins in the ER are exported out of the lumen by retrotranslocation, another mechanism downstream of UPR that reduces the erroneously folded proteins in the ER [158].

As described earlier, the studies of mature receptors suggest that tetrameric AMPA-Rs have a dimer-of-dimers organization. In the primary structure of the AMPA-R subunits, the NTD follows the signal peptide and thus is the first domain that is synthesized in the ER. The NTDs of AMPA-Rs are known to form stable dimers, and together with the more recent studies on the crystal structures of the

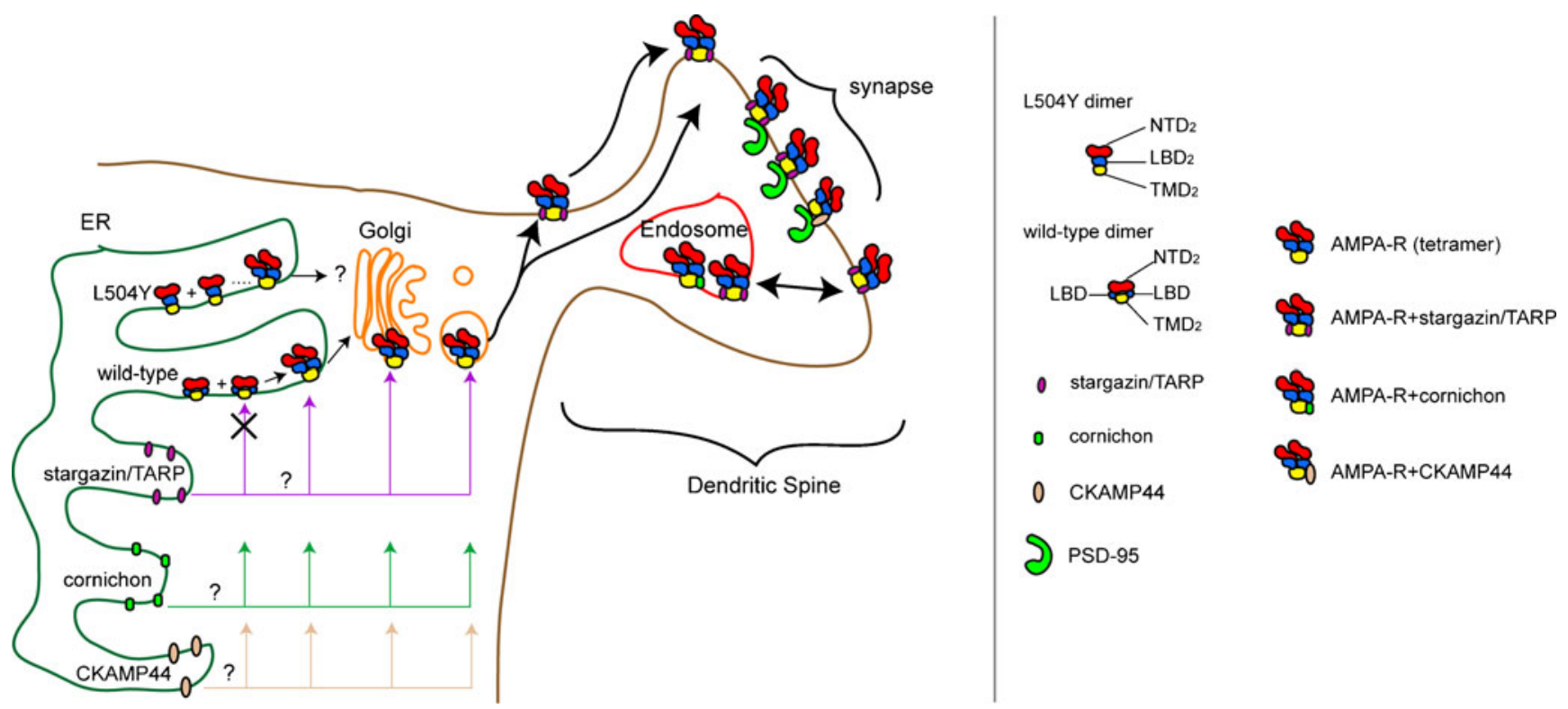

Fig. 6 Biosynthesis, subunit assembly, and trafficking of AMPA-R. Schematic of the trajectories of the AMPA-R biosynthesis, assembly, and trafficking is shown. AMPA-Rs are synthesized and assembled in the ER and exported to the Golgi apparatus. In the ER, stable dimers of AMPA-R subunits are formed and transition into tetramers. In the structure of dimeric wild-type subunits, the NTD and TMD form dimers but the LBD is separated. In contrast, the NTD, LBD, and TMD are all compactly dimerized in the GluR2L504Y mutant, which transition into tetramers much less efficiently. The domain organization seen in the structure of the wild-type dimer is critical for efficient tetramerization. A small quantity of GluR2L504Y tetramers is formed and reach the cell surface by an unknown mechanism. The majority of
GluR2L504Y is not complex mannose glycosylated, suggesting that it did not receive modification in the Golgi apparatus. It is likely that most GluR2L504Y cannot even exit the ER or reach the cis-Golgi. Stargazin/TARPs are associated with the mature AMPA-Rs. Stargazin preferentially forms a stable complex with GluR2 tetramers but not with dimers. The cornichon and CKAMP44 assemble together with AMPA-Rs but the timing and location in relation to the subunit assembly pathway of AMPA-R subunits are unclear. In the synapse, the C-termini of stargazin/TARP and CKAMP44 interact with the synaptic scaffold proteins such as PSD-95 that belongs to the membrane associated guanylate kinase (MAGUK) family 
NTDs, it was suggested that the initial dimerization of the NTDs is the first instructive step during the assembly of the AMPA-Rs into dimer-of-dimers organization [71, 72, 159161]. The functional assembly of AMPA-Rs was examined by measuring channel currents from chimeric constructs of glutamate receptors generated by domain swapping between AMPA-R and kainate receptor subunits [162]. It was concluded that both the NTD and the TMD are important for obtaining functional ion channels.

Biochemically, it has been observed that subunit dimers exist in the detergent extracted lysates of the brain, cultured neurons, and the HEK cells expressing the subunits [96, 163-165]. The structural identity of these dimers and their relation to the mature assembled receptors were not clear. The ${ }^{35} \mathrm{~S}$ labeling has shown that the half-life of AMPA-Rs in the spinal cord neuron culture is $18 \mathrm{~h}$ [166]. The speed of maturation in neurons differs between subunits. In a pulse chase experiment, the maturation of GluA1 subunit was around $12 \mathrm{~h}$, whereas the only one third of GluA2 mature in $22 \mathrm{~h}$ [165]. A recent study used a drug-inducible expression of GluA2 subunit in stable HEK cell lines to gain control over the timing and subunit composition during AMPA-R biosynthesis [23]. The receptor expression reached the maximum at around $24 \mathrm{~h}$ post-induction. The majority of the glycosylation happened during the period of 12-24 h post-induction, indicating that the post-Golgi trafficking and cell surface expression happens during this period. At the time point of $12 \mathrm{~h}$ after induction, the majority of GluA2 were dimers. The turnover rate of AMPA-Rs in neurons and the maturation speed in HEK cells are in good agreement. In addition, the AMPA-Rs expressed in HEK cells are functional ion channels [40], and thus the assembly mechanism of AMPA-Rs can be studied in both neuronal and HEK cell systems.

\section{Mutations that Affect ER Export of AMPA-Rs}

Based on the crystal structure of the LBD [51], a series of point mutants around the glutamate binding pocket of the LBD of GluA2 subunit were examined to test if there is correlation between the ability to induce ligand-dependent conformational change of the LBD and the ER export of the receptor [148, 167]. In fact, the mutations that reduced glutamate affinity also impaired ER export, whereas a mutant that facilitated ligand-induced conformational change had an accelerated ER export. The AMPA-Rs are not the first membrane receptor whose folding and ER export are modulated by the ligands and co-factors. Among the glutamate receptors, the kainate receptors were the first that were reported to require the ability to bind to glutamate in order to efficiently export from the ER [168-170]. Specifically, mutations in the LBD that block glutamate binding in kainate receptors had deficits in ER export. More recently, it was shown that the glycine binding to the GluN1 subunit was critical for surface expression of the NMDA-Rs [171]. Furthermore, the ER export of the $\delta$ opioid receptor and rhodopsin improve in the presence of membrane-permeable opioid ligands and vitamin A, respectively $[172,173]$.

In mature AMPA-Rs, the glutamate-induced conformational changes initiate a series of events starting with the closure of the clamshell-like structure of the LBD [51, 53]. Functionally, continuous exposure to glutamate results in desensitization. In terms of protein conformation, desensitization is caused by the destabilization of the LBD dimer [52]. Increasing the affinity of the LBDs in the dimer inhibits desensitization whereas reducing the affinity facilitates desensitization [57, 174]. Interestingly, the destabilization of the LBD dimers that follows clamshell closure is also suggested to play critical roles in ER export and receptor assembly [23, 148]. The non-desensitizing point mutant GluR2 L504Y (also known as L483Y when numbering the first amino acid immediately after the cleavage site of the signal peptide) traffics to the cell surface at reduced efficiency compared to the wild-type [163]. Similarly in the kainate receptor subunit GluK2, a mutation that blocks desensitization of the ion channel also reduces its surface delivery [175]. The GluA2 L504Y and analogous mutants in other AMPA-R subunits have been studied extensively from the point of view of nondesensitizing mutants $[57,127,176,177]$. Blocking desensitization in these point mutants has been correlated with the inability of the LBD dimers to separate in the crystal structures of S1S2 constructs [57].

It is not clear if the clamshell closure of the LBD is required before or after the dimer-to-tetramer transition [148]. When overexpressed in HEK cells, the mutant GluK2 subunits that cannot bind glutamate were detected as a mixture of monomer, dimer, tetramers, and high molecular weight misfolded aggregates, the latter being the majority [169]. In the case of GluA2 subunit, the T686A and T686S mutations that are predicted to destabilize the clamshell closure of the LBD did not exit ER but the oligomeric state of the immature receptor trapped in the ER was uncharacterized [148]. The non-desensitizing GluA2 L504Y mutant expressed in HEK cells were detected as mixture of monomer, dimer, tetramer, and high molecular weight unfolded (or misfolded) aggregates [148]. On the other hand, the majority of GluA2 L504Y existed as dimers when expressed at a moderate level using stable cell lines in which the expression levels of the subunit was controlled by DOX, and thus by preventing UPR and aggregates [23]. Clearly, GluA2 L504Y cannot transition efficiently from dimer to tetramer. However, it remains to be determined if the mutant GluA2 subunits that cannot bind to glutamate can transition into tetramers under similar 
experimental conditions in the absence of UPR. An intriguing possibility is that glutamate may facilitate the dimer-totetramer transition. Various evidence supports the idea that in the brain, two homodimers of different subunits [such as $(\mathrm{GluA} 1)_{2}$ and $\left.(\mathrm{GluA} 2)_{2}\right]$ combine and form heterotetrameric AMPA-Rs [such as $(\mathrm{GluA} 1)_{2}(\mathrm{GluA} 2)_{2}$ ] [39, 161, 162]. Because the subunit composition governs the characteristics of individual AMPA-Rs, the molecular mechanism of the dimer-to-tetramer transition is particularly important when considering endogenous heterotetrameric AMPA-Rs.

The flip/flop alternatively spliced site also affects receptor maturation. The flip and flop variants differ in their gating properties [32] and the flip variant matures more efficiently than the flop $[148,178]$. Four out of nine residues that differ between flip and flop variants are located in the alpha-helices $\mathrm{J}$ and $\mathrm{K}$ in the LBD [51]. These helices are part of the interface that mediates dimerization of the two LBDs. The flip variant recovers from desensitization faster compared to the flop variant [179]. The L758 in flop, or equivalently the V758 in flip, were identified as the critical residue that determines the characteristic kinetics during the recovery from desensitization in each splice variant. Switching the residue $\mathrm{L} 758$ in flop to $\mathrm{V}$ was sufficient to convert the resensitization of flop into the flip phenotype, and vice versa. The residue 758 also plays a key role in the maturation phenotype [148]. If residue 758 is switched to $\mathrm{V}$ in GluA2 flop, the resulting GluA2 flop L758V mutant matures as efficiently as the flip phenotype, and conversely. The mutants that recover faster from desensitization also export efficiently from the ER. This might imply that after being used to facilitate subunit assembly, the release of glutamate from the LBD may be another rate-determining step during the assembly of the AMPA-Rs.

The $\mathrm{R} / \mathrm{G}$ editing site is located immediately before the flip/flop splice site in the LBDs of GluA2-4 subunits [35]. The $\mathrm{G}$ form desensitizes faster and recovers faster than the $\mathrm{R}$ form $[180,181]$. The crystal structure of the unedited LBD with R743 proposed the possibility that the R743 may stabilize the dimer interface [163]. However, compared to the $\mathrm{G}$ form, the $\mathrm{R}$ form had a greater tendency to tetramerize and mature, and thus stabilization of the LBD interface is preferred for maturation.

The $\mathrm{Q} / \mathrm{R}$ editing is located in the channel pore in the cytoplasmic side that corresponds to the ion selectivity filter in the potassium channels $[35,182]$. The majority of the endogenous GluA2 subunits are the $\mathrm{R}$ form, which confers the AMPA-R calcium impermeable. Interestingly, the $\mathrm{Q}$ form is more favorable than $\mathrm{R}$ form for homotetramerization [164]. It has been suggested that the larger side group of $\mathrm{R}$ compared to the more compact $\mathrm{Q}$ may interfere with forming the narrow constriction in the 4-fold symmetric channel pore [164]. This means that the mechanism that determines the difference between the efficiency of matu-
Fig. 7 Structures of the dimer intermediates and the subunit assembly pathway of AMPA-R. a Top - the EM structure of dimer intermediate of wild-type GluA2 is shown from two different views. Bottom - placement of known crystal structures into the EM density map. Red, ligand binding domain of GluA2 (PDB:3H5W); blue, ligand binding domain of GluR2 S1S2 wild-type (PDB:1FTJ). b Top - the EM structure of dimer intermediate of GluA2 L504Y is shown from two different views. Bottom - placement of known crystal structures into the EM density map. Red, ligand binding domain of GluA2 (PDB:3H5W); blue, ligand binding domain of GluR2 S1S2 wild-type (PDB:1FTJ). c Proposed AMPA-R subunit assembly pathways are shown. In the wild-type subunit dimers, the LBDs are not dimerized. We propose that the LBD dimers in wild-type subunits are formed during the dimer-to-tetramer transition. On the other hand, the LBDs in the L504Y mutant subunits form intra-dimer dimers that may prevent efficient dimer-to-tetramer transition. NTD — red and orange, LBD - blue and purple, TMD-yellow and green. The images were reproduced from [23]

ration of the $\mathrm{Q} / \mathrm{R}$ forms is different from that of the flip/flop and $\mathrm{R} / \mathrm{G}$ variants. The $\mathrm{Q} / \mathrm{R}$ editing site was also implicated in the functional interaction with stargazin/TARPs [129], and thus may have multiple functional roles. The R form of GluA2 subunits homotetramerize inefficiently compared to the $\mathrm{Q}$, and this is proposed as a potential mechanism by which the mature $\mathrm{R}$ form preferentially heterotetramerizes with the Q forms of the other GluA subunits [142, 164].

\section{Single Particle EM Study of the Dimer Intermediates} of AMPA-Rs

The dimeric biosynthetic AMPA-Rs were purified and studied recently by single particle EM [23]. In this study, the authors establish a simplified system in which they can study the assembly of AMPA-Rs. Biosynthetic and trafficking intermediates have a shorter lifetime compared to mature and targeted proteins. Thus, biochemical enrichment is less efficient, more laborious, and requires a larger quantity of raw material. To overcome these hurdles, the GluA2 subunit was DOX dependently expressed in HEK cells and purified at an early time point in order to enrich for biosynthetic intermediates. Importantly, the dimer population appeared before the tetramers, indicating that the dimers are the stable biosynthetic intermediates of AMPA-Rs.

As described earlier, GluA2 L504Y, the non-desensitizing point mutant, has significantly decreased cell surface expression compared to the wild-type GluA2. Consistent with the observed deficit in trafficking, GluA2 L504Y is deficient in dimer-to-tetramer transition when expressed in HEK cells using a DOX-dependent expression system [23]. Even after $24 \mathrm{~h}$ after inducing the expression, the majority of the GluA2 L504Y existed as dimers and did not have mature glycosylation, whereas at this time point the majority of the GluA2 wild-type are maturely glycosylated and formed tetramers. Interestingly, the single particle EM structures of the GluA2 wild-type and GluA2 L504Y were significantly different (Fig. 7a, b). 
A

GluA2 wild-type dimer
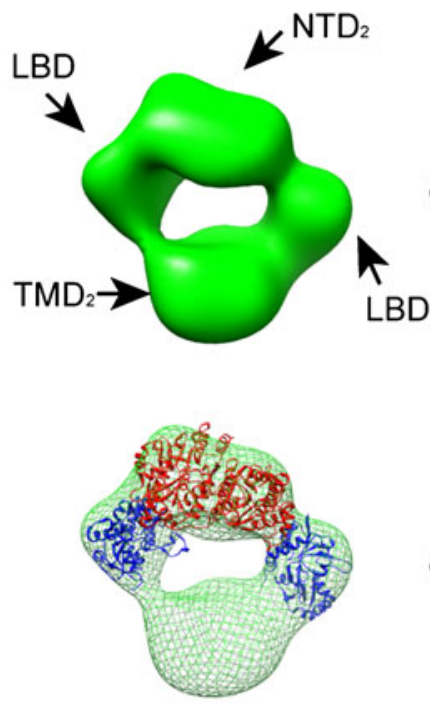

C

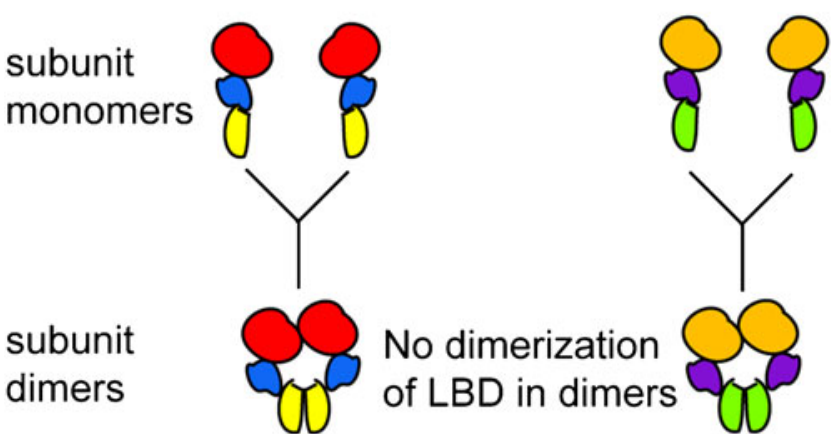

subunit tetramers



B

GluA2 L504Y dimer
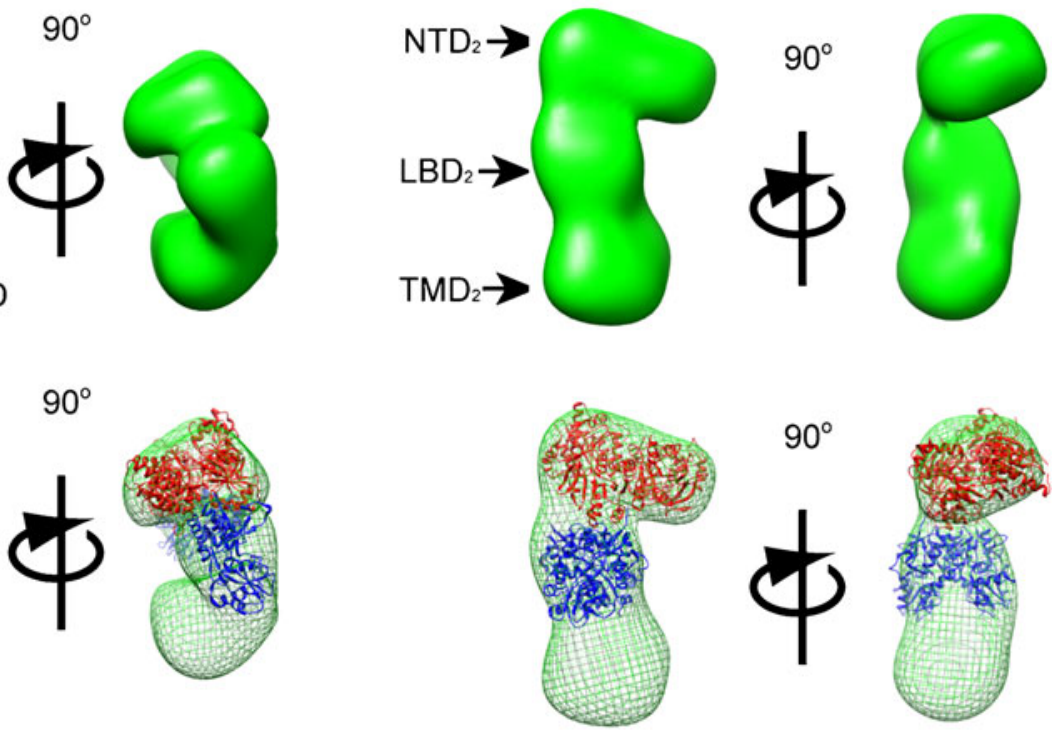

L504Y

wild-type
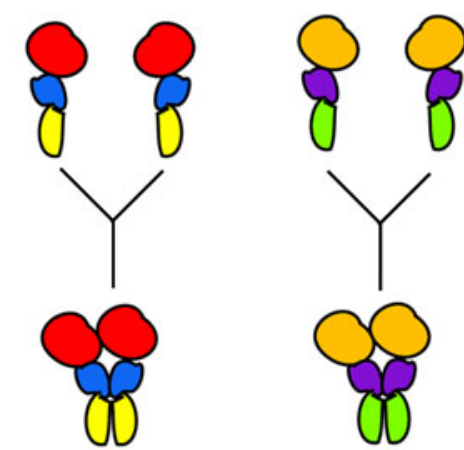

Intra-dimer subunits dimers dead-end, because LBD dimer interface not available to make tetramer interactions
The NTDs and the TMDs were dimeric in the structures of the dimer intermediates of both GluA2 wild-type and L504Y. A significant difference in the structures was observed in the arrangements of the LBDs. Specifically, the two LBDs were separated in the wild-type GluA2 dimers, whereas in the case of L504Y mutant they were fused as a single density. Importantly, the difference in molecular shapes is correlated with their contrasting ability to transition from dimer to tetramer. The comparison of the structures between the GluA2 dimers of wild-type and 
L504Y suggests that the separation of the LBD is required for efficient dimer-to-tetramer transition.

The isolated NTDs of GluA2 form stable dimers [71, 72, 159-161], and both the NTD and the TMD are necessary to form functional ion channels of GluA2 [162]. Accordingly, the NTDs and the TMDs were dimerized in the dimeric GluA2 wild-type, providing structural evidence for previously reported observations. The compact structure of the LBDs in the dimeric GluR2L504Y agrees with the high affinity dimer formed by the S1S2 construct of the isolated LBD that carries the same mutation [57]. The structure is also consistent with previous results indicating that native tetrameric AMPA-Rs treated with $1 \mathrm{mM}$ glutamate have more compact structures in the presence of cyclothiazide, an inhibitor of desensitization [66].

The two LBDs are separated in the GluR2 wild-type dimers and, therefore, intermolecular dimerization of the LBDs can potentially occur during the assembly of a tetramer between two GluR2 wild-type dimers. In contrast, the LBDs are fused in the GluR2 L504Y dimers. Since this mutation causes a defect in dimer-to-tetramer transition, it is conceivable that the separation of LBD dimers is required to drive the formation of tetramers. These results support a new model for the subunit assembly pathway of AMPA-Rs in which the dimer-to-tetramer transition accompanies formation of two new LBD dimers between the two molecular dimers of subunits (Fig. 7c). This suggests a domain arrangement in the tetrameric AMPA-Rs in which the NTD and the LBD of each subunit forms a dimer with a different neighboring subunit. Importantly, a similar connection between domains in the AMPA-R was also observed in GluA2cryst tetramer despite that linker sequences connecting the NTD and LBD were significantly engineered in their construct [75], indicating that the interdomain contacts play stronger roles in defining the global domain arrangements of the tetrameric AMPA-Rs. The chronological order of the inter-domain contacts during the subunit assembly process may also govern the global domain arrangements of the assembled receptor.

The global domain arrangements in the dimer intermediates and the proposed assembly pathway to the mature tetrameric GluA2 provide new interpretations to the previous studies of the mutant GluA2 with maturation deficits. When considering the variants produced by the RNA editing of the $\mathrm{R} / \mathrm{G}$ site, the stronger interaction between the LBDs observed in the $\mathrm{R}$ variant may be advantageous over the $\mathrm{Q}$ variant during the dimer-to-tetramer transition when dimers are formed between the LBDs of two distinct dimer intermediates of subunits. On the other hand, the premature stabilization of the intra molecular LBD dimer within the subunit dimer intermediate will prevent the inter molecular LBD dimerization that should take place during the dimerto-tetramer transition. Such a mechanism may explain why too strong of interactions between the LBDs, such as seen in the L504Y mutant, are unfavorable for the dimer-totetramer transition, but moderate interaction is preferred for maturation. Consistently, slowing the desensitization by introducing GluA2 L504A (equivalent to L483A) mutation accelerates ER export and tetramerization [148]. The mechanism by which the GluA2 L504A slows desensitization is by stabilizing the LBD dimer interface but not to the extent of the GluA2 L504Y mutant [174]. Furthermore, continuous application of competitive antagonist NBQX in culture rescued surface expression of the analogous L504Y mutation in GluA4 subunit [167]. These observations support the idea that optimal and reversible stabilization of the LBD dimer interface facilitates AMPA-R maturation [148]. A mutation that slows desensitization, however, does not necessarily correlate with efficient maturation under the same genetic background. An example of such exception is when GluA2 flip wild-type and GluA2flop L758V were compared, despite that the former desensitize at a slower rate than the latter, both mature at a similar rate [148]. It is proposed that the requirement to bind to glutamate for ER exit is a mechanism to ensure that only functional receptors reach the cell surface [168]. By only allowing receptors that are capable of destabilizing the LBD dimer interface may prevent receptors deficient in desensitization from reaching the cell surface [148].

An important remaining question is whether it is possible to extend what we learned from the homotetrameric AMPA-Rs to understanding the assembly mechanism of the heterotetrameric receptors. A quantitative mass spectrometry experiment estimates that in the PSD fraction of hippocampus, the total molecular copies of GluA2 is approximately the same as the sum of GluA1 and GluA3 [183]. The AMPA-Rs made by homotetrameric subunits have the voltage-dependent rectifying property [184]. Because the majority of the AMPA-R-mediated currents in neurons do not have this characteristic, AMPA-Rs on the neuronal surface are likely to be mostly heterotetrameric receptors [39, 185]. Why are homotetrameric AMPA-R not assembled and trafficked to the synapses? Since calciumpermeable AMPA-Rs exist in the nervous system, regulation of subunit assembly by the $\mathrm{Q} / \mathrm{R}$ editing site of GluA2 may not explain all cases. What are the mechanisms involved in switching of the subtypes of AMPA-Rs? Understanding the molecular mechanism of the AMPA-R assembly will contribute to answering these questions.

The assembly process of AMPA-Rs is also related to diseases. In humans, the GRIK3 (GluA3) G833R mutant is among one of the mutations that was found in patients diagnosed as X-linked mental retardation [14]. AMPA-Rs that carry the G833R mutation are misfolded and the channel function is also impaired. Can neurological and psychiatric disorders caused by protein misfolding be 
treated? Possibly, yes. For example, a point mutation in the photoreceptor that results in misfolding is a cause of retinal neurodegenerative disorder known as rod photoreceptor degeneration and autosomal dominant retinitis pigmentosa $[186,187]$. The accumulation of the misfolded photoreceptor in the ER induces UPR and other cellular pathology that ultimately leads to neuronal cell death. Interestingly, in a mouse disease model that carries the mutation, the phenotype can be rescued by overexpressing ER chaperone BiP [188], providing an example of genetic manipulation of the UPR to cure the disease phenotype. In this view, precise understanding of the mechanism of AMPA-R assembly may contribute to determining intervening methods that can treat patients who are affected by X-linked mental retardation.

\section{Contribution of the AMPA-R Auxiliary Subunits on Receptor Assembly}

The cascade of conformational changes of the LBD is utilized by the mature AMPA-Rs during channel gating and by the immature AMPA-Rs during maturation (ER export and assembly), as discussed in the previous section. The known auxiliary subunits (stargazin/TARPs, cornichon 2/3, and CKAMP44) can modulate channel gating. The modulation of gating often results from the modulation of conformational changes associated with gating. In this view, if an auxiliary subunit associates with AMPA-Rs during the assembly process, it may also influence the maturation of the receptor.

A chaperone-like function for the auxiliary subunits was first proposed for stargazin [189]. Both AMPA-Rs and stargazin are transmembrane proteins, raising the possibility that AMPA-R and stargazin may potentially interact as early as when they are synthesized in the ER. In addition, because stargazin facilitates AMPA-R trafficking, there is also a possibility that stargazin can promote AMPA-R biogenesis by functioning as a molecular chaperone. In fact, stargazin, AMPA-Rs, and stress response chaperone BiP co-localize in the ER, suggesting a possible role of stargazin in assisting AMPA-R folding under stress conditions [189]. On the other hand, AMPA-Rs can fold properly in the absence of stargazin/TARPs in HEK cells without stargazin [23], indicating that stargazin is not necessary for the folding of AMPA-Rs. Consistently, stargazin/TARPs form a stable complex with GluR2 tetramers but not with the dimer intermediates during biogenesis. In addition, the time course of expression of the newly synthesized GluR2 was not affected by the presence of stargazin in these cell lines.

The precise function of cornichons in neurons remains elusive. In HEK cells, cornichon 2 increases surface expression of the AMPA-Rs and also modulates channel gating [45]. However, currently it is controversial whether cornichons have similar functions in the neuronal synapse [190]. Two reports demonstrate a biochemical interaction between cornichon and AMPA-Rs from brain, and cornichons can modulate channel function when co-expressed with AMPA-Rs in HEK cells. In yeast and Drosophila, cornichon homologues play critical roles in trafficking and secretion [191, 192].

The recent study characterizing the roles of cornichons in AMPA-R function suggests that in neurons cornichons may play roles as molecular chaperones [190]. The distribution of the cornichons according to mRNA localization in the Allen Brain Atlas indicates the presence of all homologues throughout the brain, with particularly high levels in the hippocampus [193]. This may suggest a greater need for the AMPA-R chaperone function in spatially restricted areas such as the hippocampus where there are higher demands to traffic AMPA-Rs. More studies are needed to precisely determine the function of cornichon 2 and 3 in the brain.

Acknowledgments This work was supported by NIH grant R01HD061543 from NICHD (to T.N.). Anthony Farina, Natalie Shanks, and Tomohiko Maruo are acknowledged for preparing figures and giving comments to the manuscript.

Open Access This article is distributed under the terms of the Creative Commons Attribution Noncommercial License which permits any noncommercial use, distribution, and reproduction in any medium, provided the original author(s) and source are credited.

\section{References}

1. Dingledine R, Borges K, Bowie D, Traynelis SF (1999) The glutamate receptor ion channels. Pharmacol Rev 51:7-61

2. Traynelis SF, Wollmuth LP, McBain CJ, Menniti FS, Vance KM, Ogden KK, Hansen KB, Yuan H, Myers SJ, Dingledine R, Sibley D (2010) Glutamate receptor ion channels: structure, regulation, and function. Pharmacol Rev 62:405-496

3. Hsia AY, Masliah E, McConlogue L, Yu GQ, Tatsuno G, Hu K, Kholodenko D, Malenka RC, Nicoll RA, Mucke L (1999) Plaque-independent disruption of neural circuits in Alzheimer's disease mouse models. Proc Natl Acad Sci USA 96:3228-3233

4. Hsieh H, Boehm J, Sato C, Iwatsubo T, Tomita T, Sisodia S, Malinow R (2006) AMPAR removal underlies Abeta-induced synaptic depression and dendritic spine loss. Neuron 52:831-843

5. Kamenetz F, Tomita T, Hsieh H, Seabrook G, Borchelt D, Iwatsubo T, Sisodia S, Malinow R (2003) APP processing and synaptic function. Neuron 37:925-937

6. Kawahara Y, Ito K, Sun H, Aizawa H, Kanazawa I, Kwak S (2004) Glutamate receptors: RNA editing and death of motor neurons. Nature 427:801

7. Lai M, Hughes EG, Peng X, Zhou L, Gleichman AJ, Shu H, Mata S, Kremens D, Vitaliani R, Geschwind MD et al (2009) AMPA receptor antibodies in limbic encephalitis alter synaptic receptor location. Ann Neurol 65:424-434 
8. Lynch G (2006) Glutamate-based therapeutic approaches: ampakines. Curr Opin Pharmacol 6:82-88

9. Rogers SW, Andrews PI, Gahring LC, Whisenand T, Cauley K, Crain B, Hughes TE, Heinemann SF, McNamara JO (1994) Autoantibodies to glutamate receptor GluR3 in Rasmussen's encephalitis. Science 265:648-651

10. Shepherd JD, Huganir RL (2007) The cell biology of synaptic plasticity: AMPA receptor trafficking. Annu Rev Cell Dev Biol 23:613-643

11. Soundarapandian MM, Tu WH, Peng PL, Zervos AS, Lu Y (2005) AMPA receptor subunit GluR2 gates injurious signals in ischemic stroke. Mol Neurobiol 32:145-155

12. Talos DM, Fishman RE, Park H, Folkerth RD, Follett PL, Volpe JJ, Jensen FE (2006) Developmental regulation of alpha-amino3-hydroxy-5-methyl-4-isoxazole-propionic acid receptor subunit expression in forebrain and relationship to regional susceptibility to hypoxic/ischemic injury. I. Rodent cerebral white matter and cortex. J Comp Neurol 497:42-60

13. Talos DM, Follett PL, Folkerth RD, Fishman RE, Trachtenberg FL, Volpe JJ, Jensen FE (2006) Developmental regulation of alpha-amino-3-hydroxy-5-methyl-4-isoxazole-propionic acid receptor subunit expression in forebrain and relationship to regional susceptibility to hypoxic/ischemic injury. II. Human cerebral white matter and cortex. J Comp Neurol 497:61-77

14. Wu Y, Arai AC, Rumbaugh G, Srivastava AK, Turner G, Hayashi T, Suzuki E, Jiang Y, Zhang L, Rodriguez J et al (2007) Mutations in ionotropic AMPA receptor three alter channel properties and are associated with moderate cognitive impairment in humans. Proc Natl Acad Sci USA 104:18163-18168

15. Boulter J, Hollmann M, O'Shea-Greenfield A, Hartley M, Deneris E, Maron C, Heinemann S (1990) Molecular cloning and functional expression of glutamate receptor subunit genes. Science 249:1033-1037

16. Hollmann M, O'Shea-Greenfield A, Rogers SW, Heinemann S (1989) Cloning by functional expression of a member of the glutamate receptor family. Nature 342:643-648

17. Keinanen K, Wisden W, Sommer B, Werner P, Herb A, Verdoorn TA, Sakmann B, Seeburg PH (1990) A family of AMPAselective glutamate receptors. Science 249:556-560

18. Meguro H, Mori H, Araki K, Kushiya E, Kutsuwada T, Yamazaki M, Kumanishi T, Arakawa M, Sakimura K, Mishina M (1992) Functional characterization of a heteromeric NMDA receptor channel expressed from cloned cDNAs. Nature 357:70-74

19. Moriyoshi K, Masu M, Ishii T, Shigemoto R, Mizuno N, Nakanishi S (1991) Molecular cloning and characterization of the rat NMDA receptor. Nature 354:31-37

20. Nakanishi N, Shneider NA, Axel R (1990) A family of glutamate receptor genes: evidence for the formation of heteromultimeric receptors with distinct channel properties. Neuron 5:569-581

21. Sakimura K, Bujo H, Kushiya E, Araki K, Yamazaki M, Meguro H, Warashina A, Numa S, Mishina M (1990) Functional expression from cloned cDNAs of glutamate receptor species responsive to kainate and quisqualate. FEBS Lett 272:73-80

22. Collingridge GL, Olsen RW, Peters J, Spedding M (2009) A nomenclature for ligand-gated ion channels. Neuropharmacology $56: 2-5$

23. Shanks NF, Maruo T, Farina AN, Ellisman MH, Nakagawa T (2010) Contribution of the global subunit structure and stargazin on the maturation of AMPA receptors. J Neurosci 30:2728-2740

24. Nakanishi S (1992) Molecular diversity of glutamate receptors and implications for brain function. Science 258:597-603

25. Armstrong N, Sun Y, Chen GQ, Gouaux E (1998) Structure of a glutamate-receptor ligand-binding core in complex with kainate. Nature 395:913-917
26. Hollmann M, Maron C, Heinemann S (1994) N-glycosylation site tagging suggests a three transmembrane domain topology for the glutamate receptor GluR1. Neuron 13:1331-1343

27. Malinow R, Malenka RC (2002) AMPA receptor trafficking and synaptic plasticity. Annu Rev Neurosci 25:103-126

28. Scannevin RH, Huganir RL (2000) Postsynaptic organization and regulation of excitatory synapses. Nat Rev Neurosci 1:133141

29. Sheng M, Lee SH (2001) AMPA receptor trafficking and the control of synaptic transmission. Cell 105:825-828

30. Ziff EB (2007) TARPs and the AMPA receptor trafficking paradox. Neuron 53:627-633

31. Seeburg PH, Hartner J (2003) Regulation of ion channel/ neurotransmitter receptor function by RNA editing. Curr Opin Neurobiol 13:279-283

32. Sommer B, Keinanen K, Verdoorn TA, Wisden W, Burnashev N, Herb A, Kohler M, Takagi T, Sakmann B, Seeburg PH (1990) Flip and flop: a cell-specific functional switch in glutamateoperated channels of the CNS. Science 249:1580-1585

33. Monyer H, Seeburg PH, Wisden W (1991) Glutamate-operated channels: developmentally early and mature forms arise by alternative splicing. Neuron 6:799-810

34. Higuchi M, Maas S, Single FN, Hartner J, Rozov A, Burnashev N, Feldmeyer D, Sprengel R, Seeburg PH (2000) Point mutation in an AMPA receptor gene rescues lethality in mice deficient in the RNA-editing enzyme ADAR2. Nature 406:78-81

35. Sommer B, Kohler M, Sprengel R, Seeburg PH (1991) RNA editing in brain controls a determinant of ion flow in glutamategated channels. Cell 67:11-19

36. Higuchi M, Single FN, Kohler M, Sommer B, Sprengel R, Seeburg PH (1993) RNA editing of AMPA receptor subunit GluR-B: a base-paired intron-exon structure determines position and efficiency. Cell 75:1361-1370

37. Lomeli H, Mosbacher J, Melcher T, Hoger T, Geiger JR, Kuner T, Monyer H, Higuchi M, Bach A, Seeburg PH (1994) Control of kinetic properties of AMPA receptor channels by nuclear RNA editing. Science 266:1709-1713

38. Greger IH, Esteban JA (2007) AMPA receptor biogenesis and trafficking. Curr Opin Neurobiol 17:289-297

39. Wenthold RJ, Petralia RS, Blahos J II, Niedzielski AS (1996) Evidence for multiple AMPA receptor complexes in hippocampal CA1/CA2 neurons. J Neurosci 16:1982-1989

40. Swanson GT, Kamboj SK, Cull-Candy SG (1997) Singlechannel properties of recombinant AMPA receptors depend on RNA editing, splice variation, and subunit composition. J Neurosci 17:58-69

41. Hayashi Y, Shi SH, Esteban JA, Piccini A, Poncer JC, Malinow R (2000) Driving AMPA receptors into synapses by LTP and CaMKII: requirement for GluR1 and PDZ domain interaction. Science 287:2262-2267

42. Shi S, Hayashi Y, Esteban JA, Malinow R (2001) Subunitspecific rules governing AMPA receptor trafficking to synapses in hippocampal pyramidal neurons. Cell 105:331-343

43. Shi SH, Hayashi Y, Petralia RS, Zaman SH, Wenthold RJ, Svoboda K, Malinow R (1999) Rapid spine delivery and redistribution of AMPA receptors after synaptic NMDA receptor activation. Science 284:1811-1816

44. Nicoll RA, Tomita S, Bredt DS (2006) Auxiliary subunits assist AMPA-type glutamate receptors. Science 311:1253-1256

45. Schwenk J, Harmel N, Zolles G, Bildl W, Kulik A, Heimrich B, Chisaka O, Jonas P, Schulte U, Fakler B, Klocker N (2009) Functional proteomics identify cornichon proteins as auxiliary subunits of AMPA receptors. Science 323:13131319

46. von Engelhardt J, Mack V, Sprengel R, Kavenstock N, Li KW, Stern-Bach Y, Smit AB, Seeburg PH, Monyer H (2010) 
CKAMP44: a brain-specific protein attenuating short-term synaptic plasticity in the dentate gyrus. Science 327:1518-1522

47. Farrant M, Cull-Candy SG (2010) Neuroscience. AMPA receptors - another twist? Science 327:1463-1465

48. Zheng Y, Mellem JE, Brockie PJ, Madsen DM, Maricq AV (2004) SOL-1 is a CUB-domain protein required for GLR-1 glutamate receptor function in C. elegans. Nature 427:451-457

49. Zhang W, St-Gelais F, Grabner CP, Trinidad JC, Sumioka A, Morimoto-Tomita M, Kim KS, Straub C, Burlingame AL, Howe JR, Tomita S (2009) A transmembrane accessory subunit that modulates kainate-type glutamate receptors. Neuron 61:385-396

50. Ng D, Pitcher GM, Szilard RK, Sertie A, Kanisek M, Clapcote SJ, Lipina T, Kalia LV, Joo D, McKerlie C et al (2009) Neto1 is a novel CUB-domain NMDA receptor-interacting protein required for synaptic plasticity and learning. PLoS Biol 7:e41

51. Armstrong N, Gouaux E (2000) Mechanisms for activation and antagonism of an AMPA-sensitive glutamate receptor: crystal structures of the GluR2 ligand binding core. Neuron $28: 165-181$

52. Armstrong N, Jasti J, Beich-Frandsen M, Gouaux E (2006) Measurement of conformational changes accompanying desensitization in an ionotropic glutamate receptor. Cell 127:85-97

53. Armstrong N, Mayer M, Gouaux E (2003) Tuning activation of the AMPA-sensitive GluR2 ion channel by genetic adjustment of agonist-induced conformational changes. Proc Natl Acad Sci USA 100:5736-5741

54. Jin R, Banke TG, Mayer ML, Traynelis SF, Gouaux E (2003) Structural basis for partial agonist action at ionotropic glutamate receptors. Nat Neurosci 6:803-810

55. Jin R, Gouaux E (2003) Probing the function, conformational plasticity, and dimer-dimer contacts of the GluR2 ligand-binding core: studies of 5-substituted willardiines and GluR2 S1S2 in the crystal. Biochemistry 42:5201-5213

56. Jin R, Horning M, Mayer ML, Gouaux E (2002) Mechanism of activation and selectivity in a ligand-gated ion channel: structural and functional studies of GluR2 and quisqualate. Biochemistry 41:15635-15643

57. Sun Y, Olson R, Horning M, Armstrong N, Mayer M, Gouaux E (2002) Mechanism of glutamate receptor desensitization. Nature 417:245-253

58. Furukawa H, Gouaux E (2003) Mechanisms of activation, inhibition and specificity: crystal structures of the NMDA receptor NR1 ligand-binding core. EMBO J 22:2873-2885

59. Furukawa H, Singh SK, Mancusso R, Gouaux E (2005) Subunit arrangement and function in NMDA receptors. Nature 438:185192

60. Inanobe A, Furukawa H, Gouaux E (2005) Mechanism of partial agonist action at the NR1 subunit of NMDA receptors. Neuron 47:71-84

61. Mayer ML (2005) Crystal structures of the GluR5 and GluR6 ligand binding cores: molecular mechanisms underlying kainate receptor selectivity. Neuron 45:539-552

62. Mayer ML, Olson R, Gouaux E (2001) Mechanisms for ligand binding to GluR0 ion channels: crystal structures of the glutamate and serine complexes and a closed apo state. J Mol Biol 311:815-836

63. Nanao MH, Green T, Stern-Bach Y, Heinemann SF, Choe S (2005) Structure of the kainate receptor subunit GluR6 agonistbinding domain complexed with domoic acid. Proc Natl Acad Sci USA 102:1708-1713

64. Naur P, Hansen KB, Kristensen AS, Dravid SM, Pickering DS, Olsen L, Vestergaard B, Egebjerg J, Gajhede M, Traynelis SF, Kastrup JS (2007) Ionotropic glutamate-like receptor delta2 binds D-serine and glycine. Proc Natl Acad Sci USA 104:14116-14121
65. Kunishima N, Shimada Y, Tsuji Y, Sato T, Yamamoto M, Kumasaka T, Nakanishi S, Jingami H, Morikawa K (2000) Structural basis of glutamate recognition by a dimeric metabotropic glutamate receptor. Nature 407:971-977

66. Nakagawa T, Cheng Y, Ramm E, Sheng M, Walz T (2005) Structure and different conformational states of native AMPA receptor complexes. Nature 433:545-549

67. Nakagawa T, Cheng Y, Sheng M, Walz T (2006) Threedimensional structure of an AMPA receptor without associated stargazin/TARP proteins. Biol Chem 387:179-187

68. Safferling M, Tichelaar W, Kummerle G, Jouppila A, Kuusinen A, Keinanen K, Madden DR (2001) First images of a glutamate receptor ion channel: oligomeric state and molecular dimensions of GluRB homomers. Biochemistry 40:13948-13953

69. Tichelaar W, Safferling M, Keinanen K, Stark H, Madden DR (2004) The three-dimensional structure of an ionotropic glutamate receptor reveals a dimer-of-dimers assembly. J Mol Biol 344:435-442

70. Midgett CR, Madden DR (2008) The quaternary structure of a calcium-permeable AMPA receptor: conservation of shape and symmetry across functionally distinct subunit assemblies. J Mol Biol 382:578-584

71. Clayton A, Siebold C, Gilbert RJ, Sutton GC, Harlos K, McIlhinney RA, Jones EY, Aricescu AR (2009) Crystal structure of the GluR2 amino-terminal domain provides insights into the architecture and assembly of ionotropic glutamate receptors. J Mol Biol 392:1125-1132

72. Jin R, Singh SK, Gu S, Furukawa H, Sobolevsky AI, Zhou J, Jin Y, Gouaux E (2009) Crystal structure and association behaviour of the GluR2 amino-terminal domain. EMBO J 28:1812-1823

73. Karakas E, Simorowski N, Furukawa H (2009) Structure of the zinc-bound amino-terminal domain of the NMDA receptor NR2B subunit. EMBO J 28:3910-3920

74. Kumar J, Schuck P, Jin R, Mayer ML (2009) The N-terminal domain of GluR6-subtype glutamate receptor ion channels. Nat Struct Mol Biol 16:631-638

75. Sobolevsky AI, Rosconi MP, Gouaux E (2009) X-ray structure, symmetry and mechanism of an AMPA-subtype glutamate receptor. Nature 462:745-756

76. Kubalek E, Ralston S, Lindstrom J, Unwin N (1987) Location of subunits within the acetylcholine receptor by electron image analysis of tubular crystals from Torpedo marmorata. J Cell Biol 105:9-18

77. Miyazawa A, Fujiyoshi Y, Unwin N (2003) Structure and gating mechanism of the acetylcholine receptor pore. Nature 423:949955

78. Toyoshima C, Unwin N (1990) Three-dimensional structure of the acetylcholine receptor by cryoelectron microscopy and helical image reconstruction. J Cell Biol 111:2623-2635

79. Unwin N, Toyoshima C, Kubalek E (1988) Arrangement of the acetylcholine receptor subunits in the resting and desensitized states, determined by cryoelectron microscopy of crystallized Torpedo postsynaptic membranes. J Cell Biol 107:1123-1138

80. Blackstone CD, Moss SJ, Martin LJ, Levey AI, Price DL, Huganir RL (1992) Biochemical characterization and localization of a non-N-methyl-D-aspartate glutamate receptor in rat brain. J Neurochem 58:1118-1126

81. Dong H, O’Brien RJ, Fung ET, Lanahan AA, Worley PF, Huganir RL (1997) GRIP: a synaptic PDZ domain-containing protein that interacts with AMPA receptors. Nature 386:279-284

82. Xia J, Zhang X, Staudinger J, Huganir RL (1999) Clustering of AMPA receptors by the synaptic PDZ domain-containing protein PICK1. Neuron 22:179-187

83. Nishimune A, Isaac JT, Molnar E, Noel J, Nash SR, Tagaya M, Collingridge GL, Nakanishi S, Henley JM (1998) NSF binding to GluR2 regulates synaptic transmission. Neuron 21:87-97 
84. Osten P, Srivastava S, Inman GJ, Vilim FS, Khatri L, Lee LM, States BA, Einheber S, Milner TA, Hanson PI, Ziff EB (1998) The AMPA receptor GluR2 C terminus can mediate a reversible, ATP-dependent interaction with NSF and alpha- and betaSNAPs. Neuron 21:99-110

85. Song I, Kamboj S, Xia J, Dong H, Liao D, Huganir RL (1998) Interaction of the N-ethylmaleimide-sensitive factor with AMPA receptors. Neuron 21:393-400

86. Lee SH, Liu L, Wang YT, Sheng M (2002) Clathrin adaptor AP2 and NSF interact with overlapping sites of GluR2 and play distinct roles in AMPA receptor trafficking and hippocampal LTD. Neuron 36:661-674

87. Shen L, Liang F, Walensky LD, Huganir RL (2000) Regulation of AMPA receptor GluR1 subunit surface expression by a 4.1 N-linked actin cytoskeletal association. J Neurosci 20:79327940

88. Schulz TW, Nakagawa T, Licznerski P, Pawlak V, Kolleker A, Rozov A, Kim J, Dittgen T, Kohr G, Sheng M et al (2004) Actin/ alpha-actinin-dependent transport of AMPA receptors in dendritic spines: role of the PDZ-LIM protein RIL. J Neurosci 24:8584-8594

89. Nuriya M, Oh S, Huganir RL (2005) Phosphorylation-dependent interactions of alpha-Actinin-1/IQGAP1 with the AMPA receptor subunit GluR4. J Neurochem 95:544-552

90. Leonard AS, Davare MA, Horne MC, Garner CC, Hell JW (1998) SAP97 is associated with the alpha-amino-3-hydroxy-5methylisoxazole-4-propionic acid receptor GluR1 subunit. J Biol Chem 273:19518-19524

91. Lee HK, Barbarosie M, Kameyama K, Bear MF, Huganir RL (2000) Regulation of distinct AMPA receptor phosphorylation sites during bidirectional synaptic plasticity. Nature 405:955-959

92. Lee HK, Takamiya K, Han JS, Man H, Kim CH, Rumbaugh G, Yu S, Ding L, He C, Petralia RS et al (2003) Phosphorylation of the AMPA receptor GluR1 subunit is required for synaptic plasticity and retention of spatial memory. Cell 112:631-643

93. Saglietti L, Dequidt C, Kamieniarz K, Rousset MC, Valnegri P, Thoumine O, Beretta F, Fagni L, Choquet D, Sala C et al (2007) Extracellular interactions between GluR2 and N-cadherin in spine regulation. Neuron 54:461-477

94. Songyang Z, Fanning AS, Fu C, Xu J, Marfatia SM, Chishti AH, Crompton A, Chan AC, Anderson JM, Cantley LC (1997) Recognition of unique carboxyl-terminal motifs by distinct PDZ domains. Science 275:73-77

95. Chen L, Chetkovich DM, Petralia RS, Sweeney NT, Kawasaki Y, Wenthold RJ, Bredt DS, Nicoll RA (2000) Stargazin regulates synaptic targeting of AMPA receptors by two distinct mechanisms. Nature 408:936-943

96. Vandenberghe W, Nicoll RA, Bredt DS (2005) Stargazin is an AMPA receptor auxiliary subunit. Proc Natl Acad Sci USA 102:485-490

97. Walker CS, Jensen S, Ellison M, Matta JA, Lee WY, Imperial JS, Duclos N, Brockie PJ, Madsen DM, Isaac JT et al (2009) A novel Conus snail polypeptide causes excitotoxicity by blocking desensitization of AMPA receptors. Curr Biol 19:900-908

98. Morimoto-Tomita M, Zhang W, Straub C, Cho CH, Kim KS, Howe JR, Tomita S (2009) Autoinactivation of neuronal AMPA receptors via glutamate-regulated TARP interaction. Neuron 61:101-112

99. Tomita S, Fukata M, Nicoll RA, Bredt DS (2004) Dynamic interaction of stargazin-like TARPs with cycling AMPA receptors at synapses. Science 303:1508-1511

100. Gonen T, Grey AC, Jacobs MD, Donaldson PJ, Kistler J (2001) MP20, the second most abundant lens membrane protein and member of the tetraspanin superfamily, joins the list of ligands of galectin-3. BMC Cell Biol 2:17

101. Stauffer KA, Kumar NM, Gilula NB, Unwin N (1991) Isolation and purification of gap junction channels. J Cell Biol 115:141-150
102. Walz T, Smith BL, Agre P, Engel A (1994) The threedimensional structure of human erythrocyte aquaporin CHIP. EMBO J 13:2985-2993

103. Schroer TA, Schnapp BJ, Reese TS, Sheetz MP (1988) The role of kinesin and other soluble factors in organelle movement along microtubules. J Cell Biol 107:1785-1792

104. Ohi M, Li Y, Cheng Y, Walz T (2004) Negative staining and image classification - powerful tools in modern electron microscopy. Biol Proced Online 6:23-34

105. Jiang QX, Wang DN, MacKinnon R (2004) Electron microscopic analysis of KvAP voltage-dependent $\mathrm{K}+$ channels in an open conformation. Nature 430:806-810

106. Cheng Y, Walz T (2009) The advent of near-atomic resolution in single-particle electron microscopy. Annu Rev Biochem 78:723742

107. Grisshammer R, Tate CG (1995) Overexpression of integral membrane proteins for structural studies. Q Rev Biophys 28:315-422

108. Roosild TP, Greenwald J, Vega M, Castronovo S, Riek R, Choe S (2005) NMR structure of Mistic, a membrane-integrating protein for membrane protein expression. Science 307:1317-1321

109. Tate CG, Grisshammer R (1996) Heterologous expression of Gprotein-coupled receptors. Trends Biotechnol 14:426-430

110. Andersen PH, Tygesen CK, Rasmussen JS, Soegaard-Nielsen L, Hansen A, Hansen K, Kiemer A, Stidsen CE (1996) Stable expression of homomeric AMPA-selective glutamate receptors in BHK cells. Eur J Pharmacol 311:95-100

111. Hennegriff M, Arai A, Kessler M, Vanderklish P, Mutneja MS, Rogers G, Neve RL, Lynch G (1997) Stable expression of recombinant AMPA receptor subunits: binding affinities and effects of allosteric modulators. J Neurochem 68:2424-2434

112. Aricescu AR, Assenberg R, Bill RM, Busso D, Chang VT, Davis SJ, Dubrovsky A, Gustafsson L, Hedfalk K, Heinemann U et al (2006) Eukaryotic expression: developments for structural proteomics. Acta Crystallogr D Biol Crystallogr 62:1114-1124

113. Aricescu AR, Lu W, Jones EY (2006) A time- and cost-efficient system for high-level protein production in mammalian cells. Acta Crystallogr D Biol Crystallogr 62:1243-1250

114. Kato AS, Zhou W, Milstein AD, Knierman MD, Siuda ER, Dotzlaf JE, Yu H, Hale JE, Nisenbaum ES, Nicoll RA, Bredt DS (2007) New transmembrane AMPA receptor regulatory protein isoform, gamma-7, differentially regulates AMPA receptors. J Neurosci 27:4969-4977

115. Kawamoto S, Onishi H, Hattori S, Miyagi Y, Amaya Y, Mishina M, Okuda K (1991) Functional expression of the alpha 1 subunit of the AMPA-selective glutamate receptor channel, using a baculovirus system. Biochem Biophys Res Commun 181:756-763

116. Keinanen K, Kohr G, Seeburg PH, Laukkanen ML, Oker-Blom C (1994) High-level expression of functional glutamate receptor channels in insect cells. Biotechnology (N Y) 12:802-806

117. Madden DR, Safferling M (2007) Baculoviral expression of an integral membrane protein for structural studies. Methods Mol Biol 363:39-57

118. Wo ZG, Oswald RE (1994) Transmembrane topology of two kainate receptor subunits revealed by N-glycosylation. Proc Natl Acad Sci USA 91:7154-7158

119. Doyle DA, Morais Cabral J, Pfuetzner RA, Kuo A, Gulbis JM, Cohen SL, Chait BT, MacKinnon R (1998) The structure of the potassium channel: molecular basis of $\mathrm{K}+$ conduction and selectivity. Science 280:69-77

120. Zuo J, De Jager PL, Takahashi KA, Jiang W, Linden DJ, Heintz N (1997) Neurodegeneration in Lurcher mice caused by mutation in delta2 glutamate receptor gene. Nature 388:769-773

121. Matsuda S, Kamiya Y, Yuzaki M (2005) Roles of the N-terminal domain on the function and quaternary structure of the ionotropic glutamate receptor. J Biol Chem 280:20021-20029 
122. Choi YB, Lipton SA (1999) Identification and mechanism of action of two histidine residues underlying high-affinity $\mathrm{Zn}^{2+}$ inhibition of the NMDA receptor. Neuron 23:171-180

123. Low CM, Zheng F, Lyuboslavsky P, Traynelis SF (2000) Molecular determinants of coordinated proton and zinc inhibition of N-methyl-D-aspartate NR1/NR2A receptors. Proc Natl Acad Sci USA 97:11062-11067

124. Paoletti P, Perin-Dureau F, Fayyazuddin A, Le Goff A, Callebaut I, Neyton J (2000) Molecular organization of a zinc binding n-terminal modulatory domain in a NMDA receptor subunit. Neuron 28:911-925

125. Perin-Dureau F, Rachline J, Neyton J, Paoletti P (2002) Mapping the binding site of the neuroprotectant ifenprodil on NMDA receptors. J Neurosci 22:5955-5965

126. Williams K (1993) Ifenprodil discriminates subtypes of the $\mathrm{N}$-methyl-D-aspartate receptor: selectivity and mechanisms at recombinant heteromeric receptors. Mol Pharmacol 44:851-859

127. Rosenmund C, Stern-Bach Y, Stevens CF (1998) The tetrameric structure of a glutamate receptor channel. Science 280:1596-1599

128. Tomita S, Adesnik H, Sekiguchi M, Zhang W, Wada K, Howe JR, Nicoll RA, Bredt DS (2005) Stargazin modulates AMPA receptor gating and trafficking by distinct domains. Nature 435:1052-1058

129. Korber C, Werner M, Hoffmann J, Sager C, Tietze M, Schmid SM, Kott S, Hollmann M (2007) Stargazin interaction with alpha-amino-3-hydroxy-5-methyl-4-isoxazole propionate (AMPA) receptors is critically dependent on the amino acid at the narrow constriction of the ion channel. J Biol Chem 282:18758-18766

130. Koh DS, Burnashev N, Jonas P (1995) Block of native $\mathrm{Ca}(2+)$ permeable AMPA receptors in rat brain by intracellular polyamines generates double rectification. J Physiol 486(Pt 2):305312

131. Soto D, Coombs ID, Kelly L, Farrant M, Cull-Candy SG (2007) Stargazin attenuates intracellular polyamine block of calciumpermeable AMPA receptors. Nat Neurosci 10:1260-1267

132. Milstein AD, Nicoll RA (2009) TARP modulation of synaptic AMPA receptor trafficking and gating depends on multiple intracellular domains. Proc Natl Acad Sci USA 106:1134811351

133. Stroebel D, Carvalho S, Paoletti P (2010) Functional evidence for a twisted conformation of the NMDA receptor GluN2A subunit N-terminal domain. Neuropharmacology (in press)

134. Gielen M, Siegler Retchless B, Mony L, Johnson JW, Paoletti P (2009) Mechanism of differential control of NMDA receptor activity by NR2 subunits. Nature 459:703-707

135. Frank J (1996) Three-dimensional electron microscopy of macromolecular assemblies. Academic, New York

136. Pasternack A, Coleman SK, Fethiere J, Madden DR, LeCaer JP, Rossier J, Pasternack M, Keinanen K (2003) Characterization of the functional role of the $\mathrm{N}$-glycans in the AMPA receptor ligand-binding domain. J Neurochem 84:1184-1192

137. O'Brien RJ, Xu D, Petralia RS, Steward O, Huganir RL, Worley P (1999) Synaptic clustering of AMPA receptors by the extracellular immediate-early gene product Narp. Neuron 23:309-323

138. Sia GM, Beique JC, Rumbaugh G, Cho R, Worley PF, Huganir RL (2007) Interaction of the N-terminal domain of the AMPA receptor GluR4 subunit with the neuronal pentraxin NP1 mediates GluR4 synaptic recruitment. Neuron 55:87-102

139. Fischer M, Kaech S, Wagner U, Brinkhaus H, Matus A (2000) Glutamate receptors regulate actin-based plasticity in dendritic spines. Nat Neurosci 3:887-894

140. Roelandse M, Welman A, Wagner U, Hagmann J, Matus A (2003) Focal motility determines the geometry of dendritic spines. Neuroscience 121:39-49
141. Heine M, Groc L, Frischknecht R, Beique JC, Lounis B, Rumbaugh G, Huganir RL, Cognet L, Choquet D (2008) Surface mobility of postsynaptic AMPARs tunes synaptic transmission. Science 320:201-205

142. Greger IH, Ziff EB, Penn AC (2007) Molecular determinants of AMPA receptor subunit assembly. Trends Neurosci 30:407-416

143. Ju W, Morishita W, Tsui J, Gaietta G, Deerinck TJ, Adams SR, Garner CC, Tsien RY, Ellisman MH, Malenka RC (2004) Activity-dependent regulation of dendritic synthesis and trafficking of AMPA receptors. Nat Neurosci 7:244-253

144. Matsuo N, Reijmers L, Mayford M (2008) Spine-type-specific recruitment of newly synthesized AMPA receptors with learning. Science 319:1104-1107

145. Park M, Penick EC, Edwards JG, Kauer JA, Ehlers MD (2004) Recycling endosomes supply AMPA receptors for LTP. Science 305:1972-1975

146. Cull-Candy S, Kelly L, Farrant M (2006) Regulation of Ca2+permeable AMPA receptors: synaptic plasticity and beyond. Curr Opin Neurobiol 16:288-297

147. Plant K, Pelkey KA, Bortolotto ZA, Morita D, Terashima A, McBain CJ, Collingridge GL, Isaac JT (2006) Transient incorporation of native GluR2-lacking AMPA receptors during hippocampal long-term potentiation. Nat Neurosci 9:602-604

148. Penn AC, Williams SR, Greger IH (2008) Gating motions underlie AMPA receptor secretion from the endoplasmic reticulum. EMBO J 27:3056-3068

149. Nakagawa T, Futai K, Lashuel HA, Lo I, Okamoto K, Walz T, Hayashi Y, Sheng M (2004) Quaternary structure, protein dynamics, and synaptic function of SAP97 controlled by L27 domain interactions. Neuron 44:453-467

150. Schluter OM, Xu W, Malenka RC (2006) Alternative N-terminal domains of PSD-95 and SAP97 govern activity-dependent regulation of synaptic AMPA receptor function. Neuron 51:99111

151. Ehlers MD (2000) Reinsertion or degradation of AMPA receptors determined by activity-dependent endocytic sorting. Neuron 28:511-525

152. Ellgaard L, Helenius A (2003) Quality control in the endoplasmic reticulum. Nat Rev Mol Cell Biol 4:181-191

153. Bannykh SI, Rowe T, Balch WE (1996) The organization of endoplasmic reticulum export complexes. J Cell Biol 135:19-35

154. Bednarek SY, Ravazzola M, Hosobuchi M, Amherdt M, Perrelet A, Schekman R, Orci L (1995) COPI- and COPII-coated vesicles bud directly from the endoplasmic reticulum in yeast. Cell 83:1183-1196

155. Springer S, Schekman R (1998) Nucleation of COPII vesicular coat complex by endoplasmic reticulum to Golgi vesicle SNAREs. Science 281:698-700

156. Shen J, Chen X, Hendershot L, Prywes R (2002) ER stress regulation of ATF6 localization by dissociation of BiP/GRP78 binding and unmasking of Golgi localization signals. Dev Cell 3:99-111

157. Bertolotti A, Zhang Y, Hendershot LM, Harding HP, Ron D (2000) Dynamic interaction of BiP and ER stress transducers in the unfolded-protein response. Nat Cell Biol 2:326-332

158. Harding HP, Novoa I, Bertolotti A, Zeng H, Zhang Y, Urano F, Jousse C, Ron D (2001) Translational regulation in the cellular response to biosynthetic load on the endoplasmic reticulum. Cold Spring Harb Symp Quant Biol 66:499-508

159. Ayalon G, Segev E, Elgavish S, Stern-Bach Y (2005) Two regions in the $\mathrm{N}$-terminal domain of ionotropic glutamate receptor 3 form the subunit oligomerization interfaces that control subtype-specific receptor assembly. J Biol Chem 280:15053-15060

160. Kuusinen A, Abele R, Madden DR, Keinanen K (1999) Oligomerization and ligand-binding properties of the ectodomain 
of the alpha-amino-3-hydroxy-5-methyl-4-isoxazole propionic acid receptor subunit GluRD. J Biol Chem 274:28937-28943

161. Leuschner WD, Hoch W (1999) Subtype-specific assembly of alpha-amino-3-hydroxy-5-methyl-4-isoxazole propionic acid receptor subunits is mediated by their n-terminal domains. J Biol Chem 274:16907-16916

162. Ayalon G, Stern-Bach Y (2001) Functional assembly of AMPA and kainate receptors is mediated by several discrete proteinprotein interactions. Neuron 31:103-113

163. Greger IH, Akamine P, Khatri L, Ziff EB (2006) Developmentally regulated, combinatorial RNA processing modulates AMPA receptor biogenesis. Neuron 51:85-97

164. Greger IH, Khatri L, Kong X, Ziff EB (2003) AMPA receptor tetramerization is mediated by $\mathrm{Q} / \mathrm{R}$ editing. Neuron 40:763-774

165. Greger IH, Khatri L, Ziff EB (2002) RNA editing at arg607 controls AMPA receptor exit from the endoplasmic reticulum. Neuron 34:759-772

166. O'Brien RJ, Kamboj S, Ehlers MD, Rosen KR, Fischbach GD, Huganir RL (1998) Activity-dependent modulation of synaptic AMPA receptor accumulation. Neuron 21:1067-1078

167. Coleman SK, Moykkynen T, Jouppila A, Koskelainen S, Rivera C, Korpi ER, Keinanen K (2009) Agonist occupancy is essential for forward trafficking of AMPA receptors. J Neurosci 29:303-312

168. Fleck MW, Cornell E, Mah SJ (2003) Amino-acid residues involved in glutamate receptor 6 kainate receptor gating and desensitization. J Neurosci 23:1219-1227

169. Mah SJ, Cornell E, Mitchell NA, Fleck MW (2005) Glutamate receptor trafficking: endoplasmic reticulum quality control involves ligand binding and receptor function. J Neurosci 25:2215-2225

170. Valluru L, Xu J, Zhu Y, Yan S, Contractor A, Swanson GT (2005) Ligand binding is a critical requirement for plasma membrane expression of heteromeric kainate receptors. J Biol Chem 280:6085-6093

171. Kenny AV, Cousins SL, Pinho L, Stephenson FA (2009) The integrity of the glycine co-agonist binding site of N-methyl$\mathrm{D}$-aspartate receptors is a functional quality control checkpoint for cell surface delivery. J Biol Chem 284:324-333

172. Li T, Sandberg MA, Pawlyk BS, Rosner B, Hayes KC, Dryja TP, Berson EL (1998) Effect of vitamin A supplementation on rhodopsin mutants threonine-17->methionine and proline-347-> serine in transgenic mice and in cell cultures. Proc Natl Acad Sci USA 95:11933-11938

173. Petaja-Repo UE, Hogue M, Bhalla S, Laperriere A, Morello JP, Bouvier M (2002) Ligands act as pharmacological chaperones and increase the efficiency of delta opioid receptor maturation. EMBO J 21:1628-1637

174. Horning MS, Mayer ML (2004) Regulation of AMPA receptor gating by ligand binding core dimers. Neuron 41:379-388

175. Priel A, Selak S, Lerma J, Stern-Bach Y (2006) Block of kainate receptor desensitization uncovers a key trafficking checkpoint. Neuron 52:1037-1046

176. Robert A, Irizarry SN, Hughes TE, Howe JR (2001) Subunit interactions and AMPA receptor desensitization. J Neurosci 21:5574-5586

177. Stern-Bach Y, Russo S, Neuman M, Rosenmund C (1998) A point mutation in the glutamate binding site blocks desensitization of AMPA receptors. Neuron 21:907-918
178. Coleman SK, Moykkynen T, Cai C, von Ossowski L, Kuismanen E, Korpi ER, Keinanen K (2006) Isoform-specific early trafficking of AMPA receptor flip and flop variants. J Neurosci 26:11220-11229

179. Koike M, Tsukada S, Tsuzuki K, Kijima H, Ozawa S (2000) Regulation of kinetic properties of GluR2 AMPA receptor channels by alternative splicing. J Neurosci 20:2166-2174

180. Banke TG, Greenwood JR, Christensen JK, Liljefors T, Traynelis SF, Schousboe A, Pickering DS (2001) Identification of amino acid residues in GluR1 responsible for ligand binding and desensitization. J Neurosci 21:3052-3062

181. Krampfl K, Schlesinger F, Zorner A, Kappler M, Dengler R, Bufler J (2002) Control of kinetic properties of GluR2 flop AMPA-type channels: impact of R/G nuclear editing. Eur $\mathrm{J}$ Neurosci 15:51-62

182. Long SB, Campbell EB, Mackinnon R (2005) Crystal structure of a mammalian voltage-dependent Shaker family $\mathrm{K}+$ channel. Science 309:897-903

183. Cheng D, Hoogenraad CC, Rush J, Ramm E, Schlager MA, Duong DM, Xu P, Wijayawardana SR, Hanfelt J, Nakagawa T et al (2006) Relative and absolute quantification of postsynaptic density proteome isolated from rat forebrain and cerebellum. Mol Cell Proteomics 5:1158-1170

184. Verdoorn TA, Burnashev N, Monyer H, Seeburg PH, Sakmann B (1991) Structural determinants of ion flow through recombinant glutamate receptor channels. Science 252:1715-1718

185. Hestrin S, Nicoll RA, Perkel DJ, Sah P (1990) Analysis of excitatory synaptic action in pyramidal cells using whole-cell recording from rat hippocampal slices. J Physiol 422:203-225

186. Dryja TP, Hahn LB, Cowley GS, McGee TL, Berson EL (1991) Mutation spectrum of the rhodopsin gene among patients with autosomal dominant retinitis pigmentosa. Proc Natl Acad Sci USA 88:9370-9374

187. Dryja TP, McEvoy JA, McGee TL, Berson EL (2000) Novel rhodopsin mutations Gly114Val and Gln184Pro in dominant retinitis pigmentosa. Invest Ophthalmol Vis Sci 41:3124-3127

188. Gorbatyuk MS, Knox T, LaVail MM, Gorbatyuk OS, Noorwez SM, Hauswirth WW, Lin JH, Muzyczka N, Lewin AS (2010) Restoration of visual function in $\mathrm{P} 23 \mathrm{H}$ rhodopsin transgenic rats by gene delivery of BiP/Grp78. Proc Natl Acad Sci USA 107:5961-5966

189. Vandenberghe W, Nicoll RA, Bredt DS (2005) Interaction with the unfolded protein response reveals a role for stargazin in biosynthetic AMPA receptor transport. J Neurosci 25:10951102

190. Shi Y, Suh YH, Milstein AD, Isozaki K, Schmid SM, Roche KW, Nicoll RA (2010) Functional comparison of the effects of TARPs and cornichons on AMPA receptor trafficking and gating. Proc Natl Acad Sci USA 107:16315-16319

191. Powers J, Barlowe C (1998) Transport of axl2p depends on erv $14 \mathrm{p}$, an ER-vesicle protein related to the Drosophila cornichon gene product. J Cell Biol 142:1209-1222

192. Roth S, Neuman-Silberberg FS, Barcelo G, Schupbach T (1995) cornichon and the EGF receptor signaling process are necessary for both anterior-posterior and dorsal-ventral pattern formation in Drosophila. Cell 81:967-978

193. Lein ES, Hawrylycz MJ, Ao N, Ayres M, Bensinger A, Bernard A, Boe AF, Boguski MS, Brockway KS, Byrnes EJ et al (2007) Genome-wide atlas of gene expression in the adult mouse brain. Nature 445:168-176 